\title{
Mandibular condyle displacements after orthognathic surgery-an overview of quantitative studies
}

\author{
Dominik Pachnicz ${ }^{1 \wedge}$, António Ramos ${ }^{2} \wedge$ \\ ${ }^{1}$ Faculty of Mechanical Engineering, Wroclaw University of Science and Technology, Wroclaw, Poland; ${ }^{2}$ TEMA, Biomechanics Research Team, \\ Mechanical Engineering Department, University of Aveiro, Aveiro, Portugal \\ Correspondence to: Dominik Pachnicz. Wroclaw University of Science and Technology, W10/K56, Smoluchowskiego 25, 50-370 Wroclaw, Poland. \\ Email: dominik.pachnicz@pwr.edu.pl.
}

\begin{abstract}
The repositioning of bone segments during orthognathic surgeries often results in mandibular condyle positional changes and can also affect jaw muscles, soft tissues and the temporomandibular joint (TMJ). Condylar displacements are considered as one of the factors of bone remodeling and further skeletal relapse. The quantitative approach is commonly used in comparative analyses and evaluations of the relationships between examined factors. The aim of this study is the overview of the current literature including quantitative analysis in the research of mandibular condyle positional changes as a consequence of orthognathic surgeries. Thirty articles were included in the overview. Most of the articles present a comparative and evaluative analysis of treatment results concerning different surgical approaches, fixation methods or types of skeletal defects. The correlation between condylar displacements and bone remodeling, skeletal relapse and TMJ dysfunctions were considered. The most frequently repeated study variables were: short-term changes, Class III malocclusion, yaw rotation, 3D cephalometry measurements. Quantitative data might be useful in the evaluation of patterns and range of condylar displacements for specific treatment conditions. Available literature concerning the analysed topic is characterized by great heterogeneity with regards to the purpose and methodologies of the studies. More systematic approaches and long-term considerations are needed in future research.
\end{abstract}

Keywords: Condylar displacement; orthognathic surgery; quantitative analysis

Submitted May 21, 2020. Accepted for publication Oct 16, 2020.

doi: 10.21037/qims-20-677

View this article at: http://dx.doi.org/10.21037/qims-20-677

\section{Introduction}

Orthognathic surgery is one of the methods used for the correction of malocclusion and temporomandibular disorders. Changes introduced to the geometry of maxillofacial structures have an impact on the biomechanics of the stomatognathic system and the position of the mandibular condyle. The study of the relationship of the factors affecting the movement of the condyle and the correlation between displacements and treatment results are the subject of many analytical considerations.
Postoperative displacement of the condyle is considered as one of the determinants of the outcome of treatment. The position of the mandibular condyle may be affected by various factors, such as distal segment repositioning, the alignment of bony fragments, the method of bony segment fixation, the tensional balance of the muscles and surrounding tissue, and the surgeon's experience $(1,2)$. There are numerous studies concerning the influence of individual variables on changes in condylar position. A quantitative approach can also be seen to assess the effects

^ ORCID: Dominik Pachnicz, 0000-0001-8832-7670, António Ramos, 0000-0002-6174-8878. 
of condylar displacements on the temporomandibular joint (TMJ) structures and skeletal stability. Early postoperative relapse and temporomandibular dysfunctions might be observed in the short-term, while late relapse associated with significant morphologic changes of the mandibular condyle and bone remodeling usually occur over a longer period (3-5).

The available literature mainly evaluates changes in the joint space, as well as changes in the translational and rotational displacements of the mandibular condyle. In the beginning, studies were based on two-dimensional radiography. Currently, computer techniques enable measurements to be taken from $3 \mathrm{D}$ models reconstructed from computed tomography scans. Three-dimensional methods have not only enabled the taking of more precise measurements $(6,7)$, but also the observation of condylar surface changes (8), therefore allowing an accurate evaluation of bone remodeling. Considerations of the relationship between the positional changes of the condyle and the magnitude of the reposition of maxillofacial bone segments usually focus on selected displacements $(9,10)$. Due to the complex character of condylar movement, data for all angular and linear displacements of the condylar head might provide a more reliable outcome.

Currently, computer techniques are broadly used in the study of biological structures $(11,12)$. They allow a more accurate insight into the condition of loaded tissues $(13,14)$. The authors of several studies utilized numerical methods in the analysis of orthognathic surgery results (15-17). Quantitative data can be used both to determine the boundary conditions, as well as for the subsequent analysis of the obtained results and validation of the numerical model. Results of such analysis, combined with biomechanical considerations of the orthognathic surgery, may also be used in predicting treatment outcome and potential risk.

The aim of this study was an overview of the literature presenting the quantitative analysis of condylar rotational and translational displacement resulting from orthognathic surgeries. The authors attempted to analyze recent literature fields of interest and collect data (with a description of each study's purpose and research characteristics), while at the same time provide information that might be useful in both clinical treatment preparations and in further analytical research planning.

\section{Methodology}

The methodology implemented in this work was adapted from systematic reviews. Relevant literature searching was focused on the quantitative aspect of the presented results.

Three methods of data presentation can be distinguished:

(I) Mean position value [standard deviation (SD)] for specific pre- and post-surgery periods;

(II) Mean change value (SD);

(III) Mean change (SD) + extreme displacement values.

In the second method, extreme changes can be approximated with an assumed level of significance using basic statistical operations. The first method does not allow a fully reliable assessment of a rotational and translational displacements. The value of the mean changes can be calculated, yet the SD of changes is unknown. This method of data presentation, however, might give an overview of the displacements pattern. Joint space is usually measured on $2 \mathrm{D}$ radiographs, so the differences in values can result from both condyle rotation and translation.

Old articles often contain analyses that include factors that are no longer relevant (e.g., fixation with lag screw or wire) or that use less precise measurement methods. Analysis of bone remodeling provides more reliable results when implementing modern methods based on the analysis of 3D models. Three-dimensional measurements are also valuable in the evaluation of condylar movement. Constant development can be observed in the field of imaging, as well as in orthognathic procedures, e.g., virtual methods of bone segment positioning, surgery planning $(18,19)$. Considering this development, the authors decided to limit the searching time-frame to the last 10 years in order to present the currently obtained results.

The following inclusion criteria were chosen when selecting articles:

* Studies published since 2010 (search updated on 11.05.2020);

* English language articles only;

* Using displacements measured for condyles;

* Data presented in two forms: mean (SD) value of displacement; mean (SD) + extreme values;

* Human trials only.

Articles presenting measurements of the proximal segment, ramus, angle, and joint space were excluded from the analysis. Studies aimed at quantitative analysis of condyle rotation and translation resulting from orthognathic surgeries were sought. The data search included a combination of terms in three conditions: orthognathic surgery ("orthognathic", "advance*", "setback", "osteotomy", "bimax*", "distract*"), "condyl*" AND "mandible" and the character of changes ("position", 


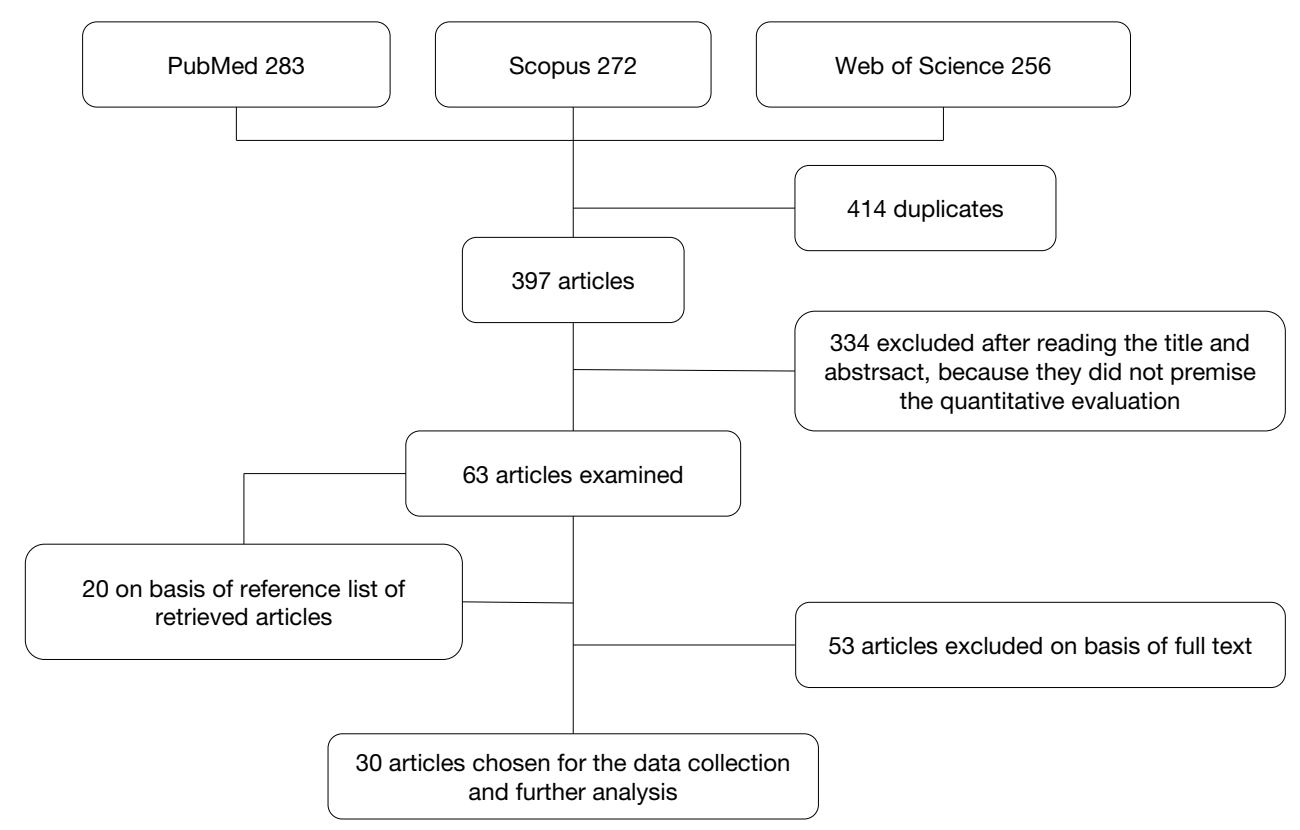

Figure 1 Flow chart of the searching.

"dislocation*", "rotation*"). A detailed electronic search was carried out in the PubMed, Scopus and Web of Science databases. The search was updated on 19.02.2020 and expanded by manual searching including the reference list of the publications preliminarily included in the analysis.

\section{Literature search outcome}

The searching for the aforementioned terms resulted in 283, 272 and 256 records for PubMed, Scopus and Web of Science, respectively, giving a total of 811 articles; 397 were unique records that were considered for further critical reading of the title and abstract; 334 articles were excluded because no premise of quantitative evaluation was found; 63 articles were included for full-text reading. An additional 20 articles were obtained by reference list screening. Twenty articles were excluded because of data presentation in the form of mean position and joint space measurements. One paper was excluded from the review because of the ambiguity connected with the negative value of SD. After the final selection according to the inclusion/exclusion criteria, twenty-nine articles were chosen and reviewed (Figure 1).

The overview of the included articles allowed the authors to distinguish two groups of studies. In the first one group, displacements were considered as a comparative factor (osteosynthesis methods, types of facial deformations, surgical interventions and surgical approaches, joint condition), or were of an evaluative nature (effectiveness of the methods/modifications, clinical reports, pattern and extent of displacement). In the second group, positional changes of the condyle (both direction and magnitude are considered) were analyzed as the potential correlation factor (with skeletal relapse, condylar volume change, TMJ signs and symptoms, condylar remodeling).

Condylar displacements as a comparative/evaluation factor were used in 22 articles (citations), and most of the studies were of an evaluative character (evaluation of the effectiveness of the surgical technique, magnitude or pattern of displacements after specific surgery). Condylar changes according to different malocclusion types or bony defects (citations) were one of the subjects of the comparison. Five articles included the collation of treatment methodsdifferences between treatment approaches (orthodontic-first approach OFA/surgery-first approach SFA) and the surgical methods [bilateral sagittal split osteotomy (BSSO)/BSSO + LeFort I]. A comparison of the fixation methods was found in two articles. In the majority of articles, inclusion criteria were based on the type of maxillomandibular deformity or surgical intervention. Class III malocclusion and BSSO/ BSSRO combined with LeFort I were often assumed as the constant agent in the compared groups. Details of the surgical procedure, measuring technique, reference landmarks and surgical changes were usually reported. 
Radiograms from CBCT were most frequently utilized for the evaluation of changes. Other methods were based on the superimposition of the 3D models, and the voxel-based registration of subvolumes. The Frankfort horizontal plane was most often assumed as one of the reference planes for the measurement and orientation of the reference system. Condylar translations were determined on the basis of the differences between the characteristic landmarks, or on the basis of the displacements of the centre of the condylar head. Rotations were evaluated from reposition of the condylar long axis, or calculated from the landmark directories. In most of the articles, advanced statistical methods were implemented for the analysis of the results, however, great heterogeneity can be noticed among them. An example of this can be seen in the evaluation of the significance of the time course of positional changes.

The second, less numerous group (seven articles) includes studies about the relationships between various study variables. In most cases, multivariate statistical methods were used to analyze correlations between factors. The effect of the condylar displacements was evaluated based on the clinical dysfunction indexes, condylar head remodeling, postoperative joint signs and skeletal relapse. The following factors, which probably affect the condylar position, were considered in publications: skeletal movement, proximal segment rotation, condylar volume, vertical bony step, age, gender, mandibular plane angle. The registration of changes related to bone remodeling and their subsequent analysis requires advanced methods. In most cases, the measurements were based on three-dimensional models, their superimposition, and advanced algorithms of data interpretation. Detailed characteristics of the studies included in the overview are shown in Table 1 and Table 2.

Data were presented as mean and SD rounded to two decimal places. In $9(31 \%)$ studies, extreme values were also given, and $11(38 \%)$ studies included measurements of all linear and angular displacements. About half of the works included all rotational or translational changes ( $41 \%$ and $59 \%)$. The most frequently reported parameter was Yaw rotation (90\%), followed by Roll rotation (66\%), and superior-inferior (62\%), anterior-posterior $(59 \%)$, and medial-lateral translations (55\%). Pitch rotation was reported in less than half of the works ( $41 \%)$, with perioperative changes being the most frequently reported (immediate $66 \%$ ). The measurements were made in intervals of 3 months, 6 months and 1 year after the surgical procedure $(21 \%, 38 \%, 21 \%)$. One study contained measurements after an average of 6 weeks, and one after more than one year. The greatest displacements are observed immediately after surgery. In the postoperative period, the condyle showed the tendency to return toward the preoperative position. The summary of the results for the various periods is presented in 11 papers $(2,8,5$ and 3 for $\mathrm{Imm} / 3$ months, $\mathrm{Imm} / 6$ months, $\mathrm{Imm} / 1$ year and 3 months $/ 6$ months, respectively).

Data interpretation is a difficult task due to the multiplicity of factors differentiating the studies. The main direction of surgical changes, i.e. distinguishing data for patients with Class II and Class III malocclusion, can be adopted as the basic criterion for classification. The analysis of the average changes in positions should be carried out for individual time intervals. Quantitative evaluation for the group of retrognathic patients and for the specific postoperative period can be performed based on data from 4 articles. In a greater number of articles, that is 14 , data for Class III malocclusion are presented. The values of immediate displacements for the single or two-jaw BSSO procedure could be found in 9 publications. The data from 6 articles also meet these criteria for the 6-month post-treatment period. The results with quantitative data collected from the analysed articles are presented in Figure S1 and Figure S2.

\section{Discussion}

The influence of orthognathic surgeries on the TMJ and the stability of treatment results has been the subject of considerations and controversies over many years. The main goal of those studies was to analyze the factors that have an impact on the treatment and its outcome, and furthermore to improve the surgical techniques and treatment process. However, many variables can affect the results. Apart from frequently considered biological or demographic aspects, a multitude of issues related to the procedure itself can be distinguished, e.g., type of surgical intervention, type of fixation method, magnitude and direction of surgical changes, considered time intervals of measurement. Quantitative analyzes present measurable data that are useful for both evaluation and comparative purposes, as well as for considering the relationship between variables.

The comparative studies evaluate the differences between specific aspects, including fixation methods, skeletal defects, and surgical treatment. Regarding fixation methods, the results presented in the clinical research were consistent with the experimental studies performed on mandible models. Although the surgical changes did not show any significant differences, these were noticeable 
Table 1 Description of the overviewed articles

\begin{tabular}{|c|c|c|}
\hline & Author & Study purpose \\
\hline $\begin{array}{l}\text { Studies } \\
\text { considering } \\
\text { correlations }\end{array}$ & $\begin{array}{l}\text { Dicker et al. } \\
(20)\end{array}$ & $\begin{array}{l}\text { The aim was to analyze the effects of changes } \\
\text { of direction of the masseter (MAS) and medial } \\
\text { pterygoid muscles (MPM) and the changes } \\
\text { of moment arms of MAS, MPM and bite } \\
\text { force on static and dynamic forces on the } \\
\text { temporomandibular joint (TMJ). Moreover, } \\
\text { the positional changes of the condyle were } \\
\text { assessed (relations between mandibular } \\
\text { advancement and sagittal rotation of the } \\
\text { proximal segment) }\end{array}$ \\
\hline
\end{tabular}

Xi et al. (21) Quantitative analysis of the 3D proximal segment rotation after BSSO advancement and assessment of its role on condylar remodeling and skeletal relapse

Han et al. (22) Identification of the TMJ signs and symptoms as a result of angular and linear condylar changes after orthognathic surgeries

Gomes

et al. (23)

Xi et al. (3)

Hwang et al.

(24)

Kalach
Mussali
et al. (10)

Investigation of the possible factors (age, presurgical anteroposterior and vertical facial characteristics, the magnitude of the surgical procedure, condylar displacement) that may be predictors of the condylar remodeling after counterclockwise maxillomandibular advancement (CCW-MMA/CMMA) and disc repositioning surgery
The study aims to quantify post-operative volume changes in condyles, quantify post- operative bone recurrences, and determine whether the recurrence of the mandible and/or maxillary bone is related to the loss of condyle volume after bilateral jaw surgery

The study aimed to assess the relationship between the type of displacement of the condyles as a result of orthognathic surgery and the subsequent adaptive remodeling of the condyle head

Investigation of the relationship between the clinical dysfunction index and the mandibular condyle position after BSSO
Outcome and conclusions

No significant changes in condylar displacement as well as joint loading were observed for two groups of patients with Class I and Class II malocclusion. Minor positional changes of the mandibular condyle do not support the idea of increased loading and increased remodeling as a result

Following the BSSO advancement surgery, proximal tends to rotate anteriorly, flare laterally and torque outward. Opposite to the other two rotational changes, the counterclockwise rotation continues and is associated with the risk of skeletal relapse. Little effect of the proximal segment rotation on condylar remodeling was observed

Angular or linear changes had no statistically significant effect on the development of postoperative TMJ symptoms. Changes in the range of $1.0 \mathrm{~mm}$ and $4^{\circ}$ do not appear to be clinically significant. It seems that the rotation of the condylar axis has a greater influence on the changes, especially with rigid fixation. However, the relationship between individual changes in position and the symptoms of TMJ cannot be established based on research

Condyles on average tended to be displaced posteriorly, superiorly, medially (most of the translational changes were less than $1 \mathrm{~mm}$ ) and had lateral yaw, medial roll and upward pitch rotation. Statistically significant but weak correlation can be observed between condylar displacement changes and condyle remodeling. Other risk factors may play important role in condylar resorption

A significant correlation between condylar volume lost and mandibular skeletal relapse was observed. In the group of particular risk are young women with large bimaxillary advancement. Condylar volume loss can be associated with the clinical signs of progressive condylar resorption

Lateral, posterior and downward with inward rotation tendency of the condyle after mandible setback. The direction of the condylar displacement is determinant for condylar remodeling and its extent. Mostly bone resorption on the superior surface of the condylar head was observed

No quantitative relationship could be established. Condylar displacements are not predicnor reproducible, because are affected by multiple factors

Table 1 (continued) 
Table 1 (continued)

\begin{tabular}{|c|c|c|}
\hline & Author & Study purpose \\
\hline $\begin{array}{l}\text { Comparative/ } \\
\text { evaluative } \\
\text { studies }\end{array}$ & Kim et al. (2) & $\begin{array}{l}\text { Evaluation of the condylar positional changes } \\
\text { after single-jaw and double-jaw surgery in } \\
\text { mandibular prognathic patients; assessment } \\
\text { of the direction and amount of condylar } \\
\text { displacement in the axial, sagittal, and frontal } \\
\text { planes }\end{array}$ \\
\hline
\end{tabular}

Yang et al. Investigation of the condylar positional changes

(25) after SSRO with posterior bending osteotomy (PBO) and grinding

Choi et al. (26) Evaluation of the postoperative stability of the mandibular condyle as an effect of different number of screws in the proximal part using

Kim et al. (27) Comparison of pre- and postoperative condyle positions after bilateral sagittal split osteotomy correction of class III malocclusion with Computer-Aided Design/Computer-Aided Manufacturing (CAD/CAM) made condyle positioning jig

Han et al. (28) The aim of the study was to evaluate the effect of bilateral sagittal split ramus osteotomy (BSSRO) on the postoperative return movement of the perioperative condyle with regards to the fixation method. Evaluation is made using 3D computed tomography analysis

Kim et al. (29) Investigation of 3D postoperative changes in the proximal sections in patients with anteriorposterior facial asymmetry

Sander et al. (30)

The aim of the study was to evaluate changes in the position of the TMJ after BSSO of the mandible using pre- and postoperative conebeam computed tomography (CBCT)

Wang et al. Study aimed to investigate effects of surgical (31) approach to the mandibular retraction on the postoperative changes
Outcome and conclusions

In the group of single-jaw surgery patients was observed more stable condylar angulation in axial view comparing to double-jaw surgery. Bimaxillary corrections resulted in greater angulations in the sagittal plane. Translational displacements showed no significant changes in both groups

Correctio of the mandibular asymmetry might be successfully performed with PBO technique, however, cases with large bony interferences may not be corrected completely

Inferior movement of the mandibular condyle was observed immediately after the surgery and constant changes in the condyle angle in the axial plane $(\mathrm{P}<0.05)$. The frontal angle decreased in both groups, curving inwards, and the condyle protruding outwards. The position of the mandibular condyle regressed to the state before surgery during the observation $(\mathrm{P}<0.05)$. There is no meaningful difference between the two considered groups, the 3-bolt fixation method presents itself as more convenient as it saves operative time and improves condylar position adaptation by allowing little distal movement

Condylar heads tend to translate laterally, posteriorly and inferiorly, and rotate medially (yaw), backward (pitch) and maintain original angulation in frontal plane. Use of CAD/CAM- made condylar positioning jig (CPJ) in orthognathic surgery gives positive, reliable results. Long-term follow-up studies of the issue are needed

Fixation technique affect condylar displacement recovery possibilities. Semi-rigid fixation with miniplate allows on condyle return to original position in greatest extent. Adaptation possibilities lowers for hybrid technique, one bicortical screw then two and more respectively

The direction (not extent) of surgical movement of the distal segment of the mandible might be the most important factor affecting the proximal segment changes between sides of asymmetric patients

Research showed minimal changes in the position of the TMJ and the angles of the jaw that were assessed after BSSO by CBCT scans

Overlaying 3D images can be useful for more accurate displacement measurements. Both SFA and OFA resulted in equally small, negligible displacement of the condyles 6 months after surgery. Future research should include a longer period of observation and assessment of the morphology of the condyles and the position of the intervertebral disc

\footnotetext{
Table 1 (continued)
} 
Table 1 (continued)

\begin{tabular}{|c|c|c|c|}
\hline & Author & Study purpose & Outcome and conclusions \\
\hline & Li et al. (1) & $\begin{array}{l}\text { The aim of the study was to investigate the } \\
\text { effect of bilateral sagittal split ramus osteotomy } \\
\text { (BSSRO) with and without Le Fort I osteotomy } \\
\text { via the surgery-first approach on the position of } \\
\text { the condyles for patients with facial asymmetry }\end{array}$ & $\begin{array}{l}\text { BSSRO-only and BSSRO with LeFort I osteotomy } \\
\text { groups resulted in condyles displacement similar to } \\
\text { one after surgical orthodontic treatment with SFA. } \\
\text { Although the magnitudes of displacement and rotation } \\
\text { were different for the tilted and non-deformed sides, } \\
\text { both sides showed inferior lateral displacement and } \\
\text { inward rotation }\end{array}$ \\
\hline & Lim et al. (9) & $\begin{array}{l}\text { Evaluation of the changes in the long axis } \\
\text { of the condyle and relationship with the } \\
\text { magnitude of the SSRO mandibular retraction } \\
\text { or asymmetric retraction }\end{array}$ & $\begin{array}{l}\text { No significant correlation between the change in the } \\
\text { length of the condylar axis after SSRO and the large } \\
\text { amount of setback was found during the research. The } \\
\text { right/left offset difference showed a positive correlation } \\
\text { with the change in the long condylar axis. In particular, } \\
\text { the correlation was statistically significant on the side } \\
\text { of lesser setback }\end{array}$ \\
\hline \multirow[t]{3}{*}{$\begin{array}{l}\text { Comparative/ } \\
\text { evaluative } \\
\text { studies }\end{array}$} & Park et al. (33) & $\begin{array}{l}\text { Investigation of the effect of orthognathic } \\
\text { surgery with intended manual condylar } \\
\text { positioning in patients with mandibular setback } \\
\text { surgery }\end{array}$ & $\begin{array}{l}\text { The inferior movement of the condyle was observed. } \\
\text { Condyles were rotated downward and inward } \\
\text { after surgery and recovered to its original position. } \\
\text { No significant difference in the change of the } \\
\text { condylar position between the } 1 \text {-jaw and } 2 \text {-jaw } \\
\text { procedures was observed. Intended manual condylar } \\
\text { positioning minimized the movement of the condyle } \\
\text { postoperatively and obtained skeletal stability }\end{array}$ \\
\hline & Choi et al. (35) & $\begin{array}{l}\text { Analysis of the anterior-posterior (AP), } \\
\text { superoinferior and mid-lateral locations and } \\
\text { angles of the condylar head determined within } \\
1 \text { month preoperative (T0) and postoperative } \\
\text { (T1) and } 6 \text { months (T2) after evaluation changes } \\
\text { in condylar heads after BSSRO }\end{array}$ & $\begin{array}{l}\text { The amount and the pattern of change in the location } \\
\text { of the condylar head in groups with large and small } \\
\text { menton deviation (MD) after orthognathic surgery were } \\
\text { very similar }\end{array}$ \\
\hline & $\begin{array}{l}\text { Gomes } \\
\text { et al. (36) }\end{array}$ & $\begin{array}{l}\text { Effect of disc repositioning on the 3D condylar } \\
\text { displacement during CMMA }\end{array}$ & $\begin{array}{l}\text { Lateral yaw, medial roll and upward pitch were } \\
\text { observed immediately after surgery. Condyle tends to } \\
\text { posterosuperior displacement and medial angulation } \\
\text { after CMMA. The CMMA procedure seems to } \\
\text { produce stable results, mainly in patients with no prior } \\
\text { problems with the TMJs or in patients undergoing } \\
\text { simultaneous surgery. Changing the position of the } \\
\text { disk provides better observation results }\end{array}$ \\
\hline
\end{tabular}

Table 1 (continued) 
Table 1 (continued)

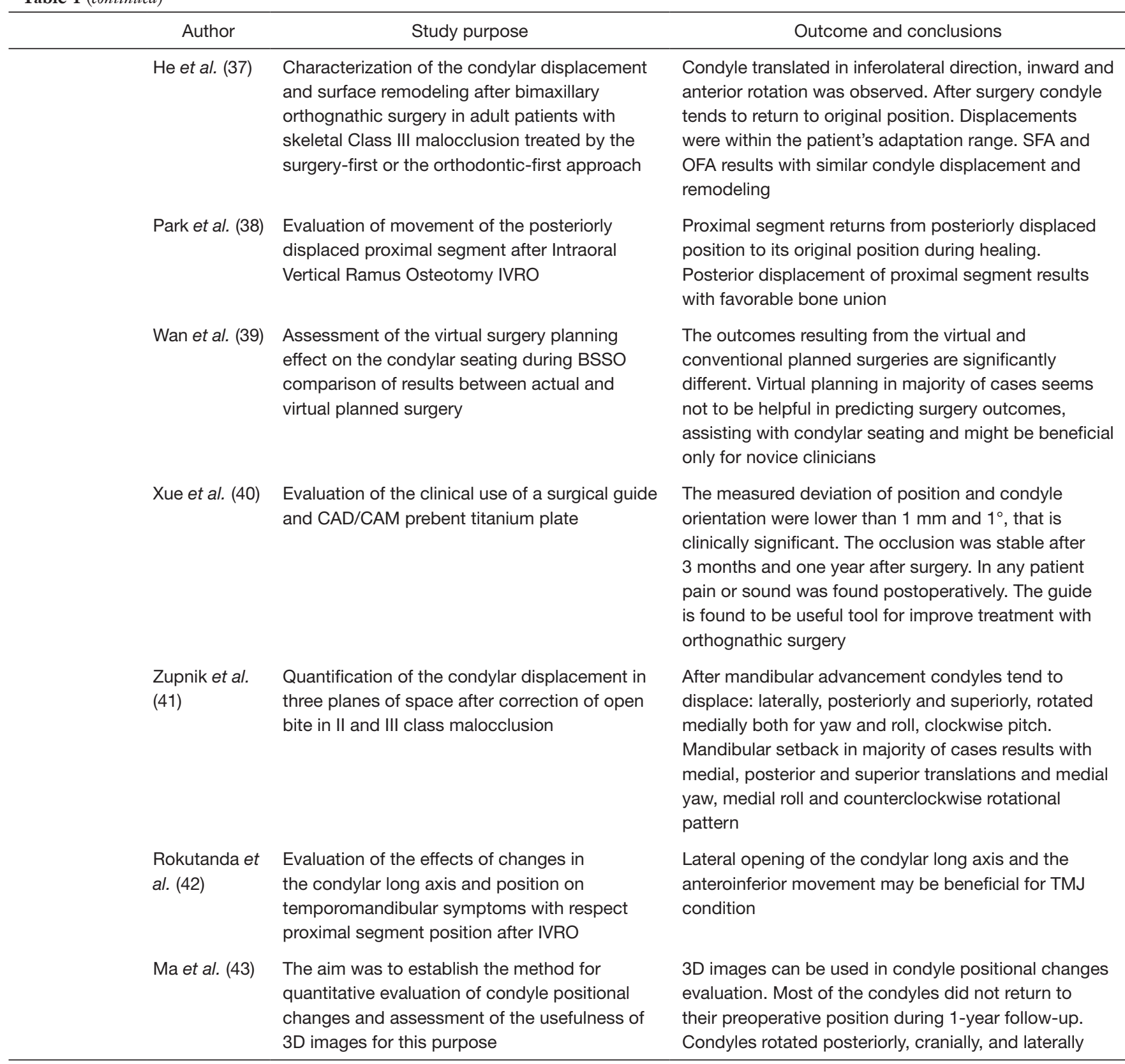

for changes in the postoperative retention period. Rigid fixation with bicortical screws provides greater stability than hybrid and semi-rigid techniques. It results in the lower ability of the condylar adaptation movement and a return toward the preoperative position. Rigid fixation is characterized by greater stability, but it also entails the risk of undesirable condylar torque and displacement during the fixation $(44,45)$, and poses a risk of nerve damage due to the compression of bone segments. Intuitive differences concern the direction and range of displacements. They are especially visible when comparing Class II and Class III malocclusions (41). Changes resulting from the correction of the asymmetry are less predictable due to the complex, spatial reposition of the distal bone segment. Both sides of the mandible might present different positional changes due to varying bony interferences and bony gaps (46). 


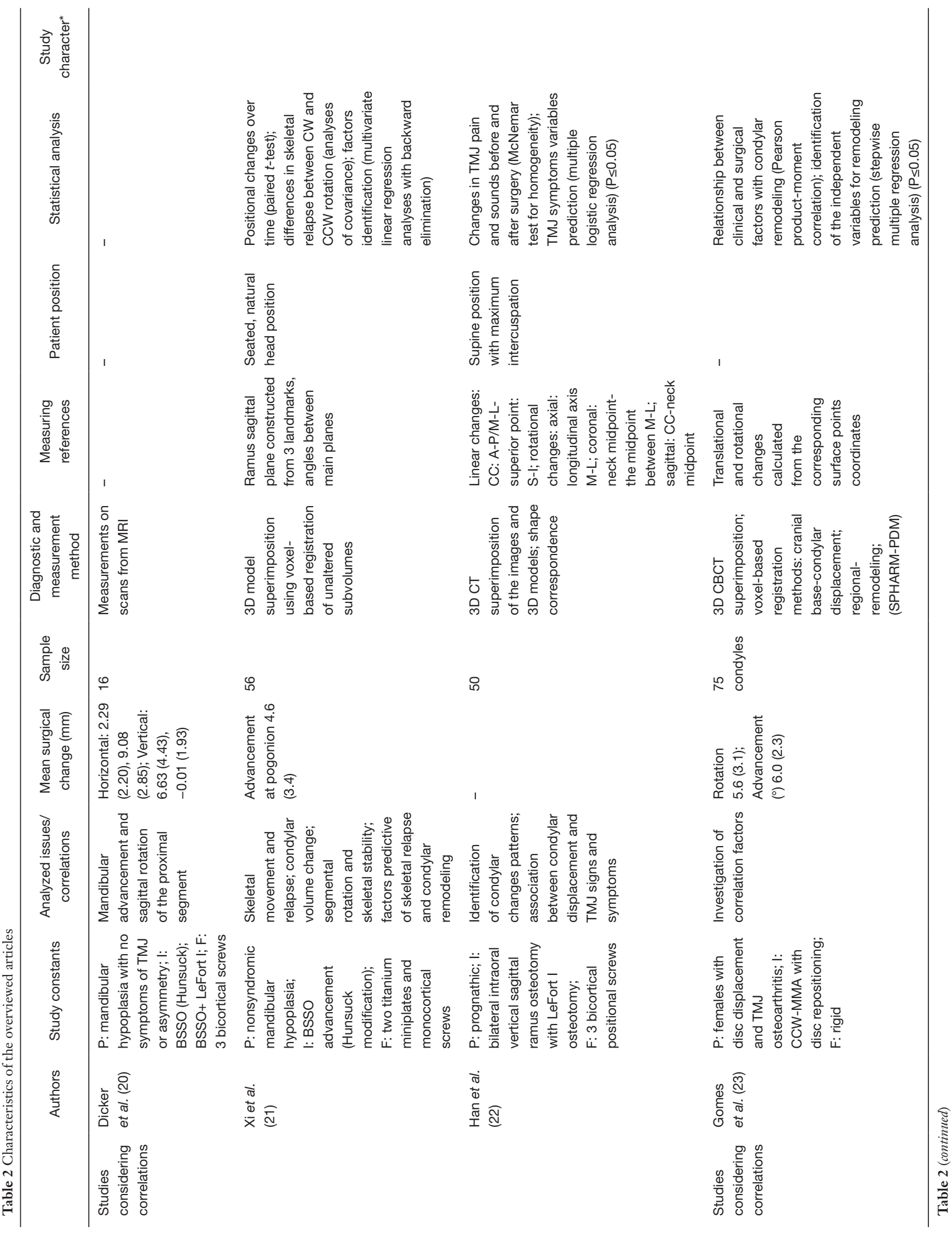




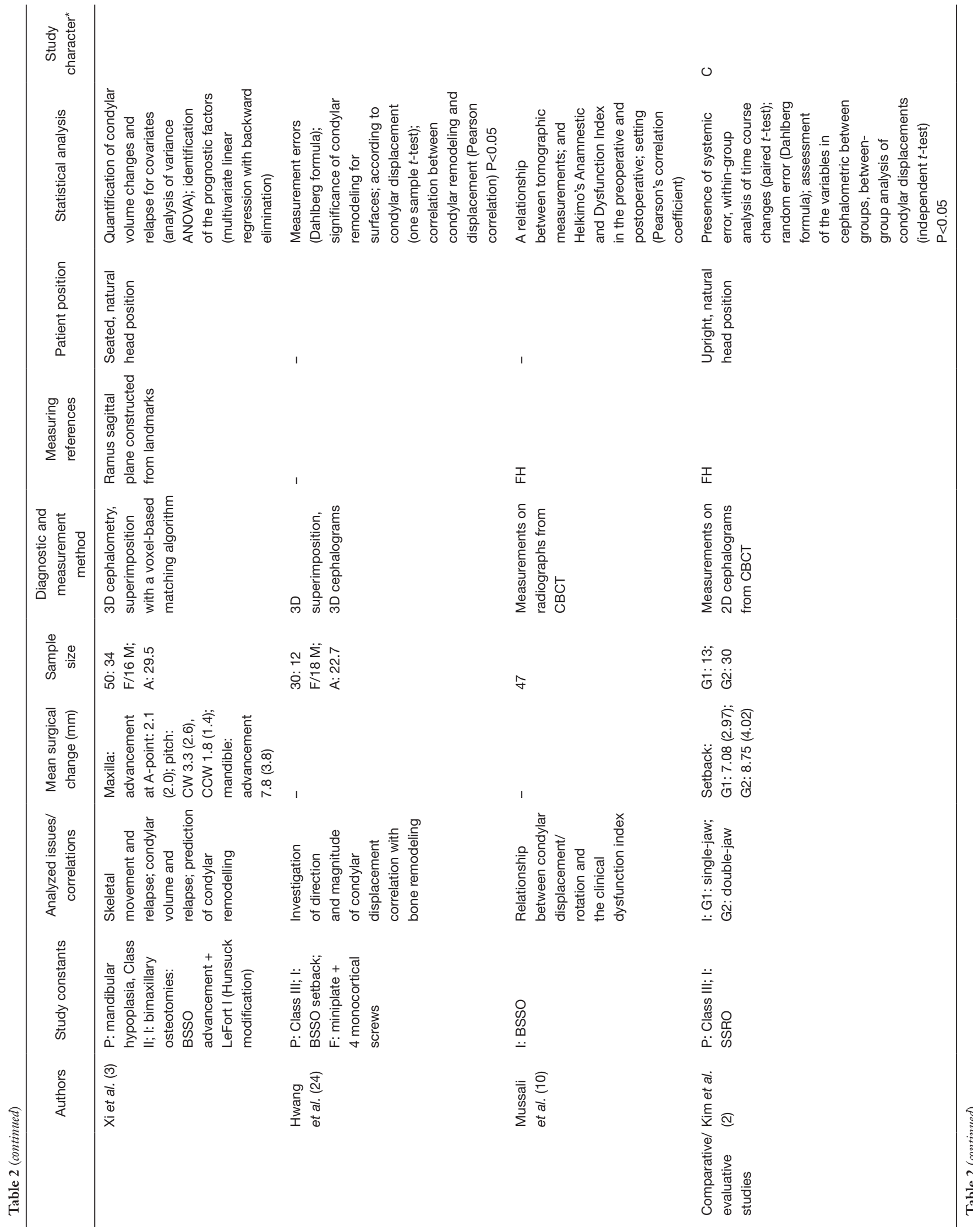




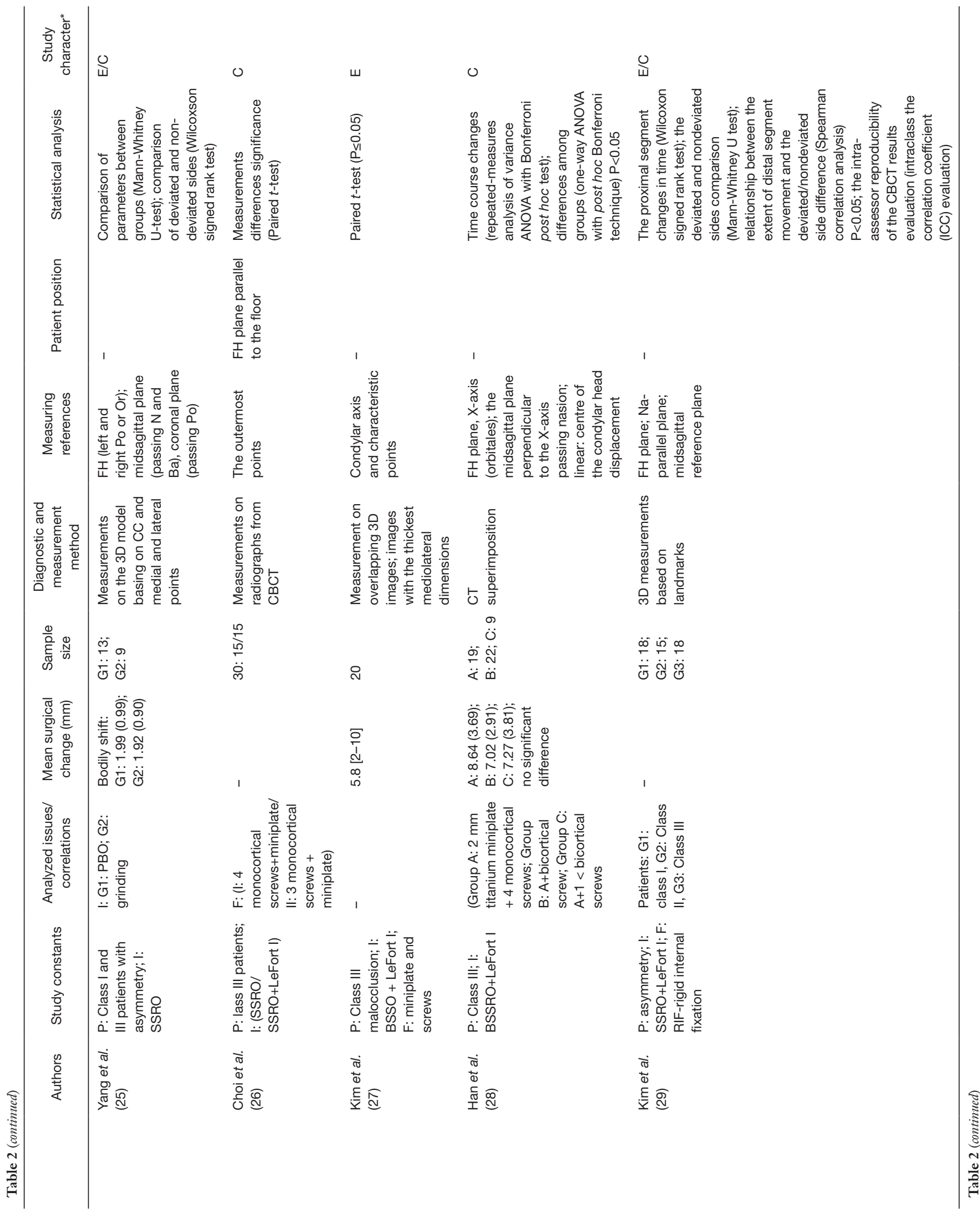




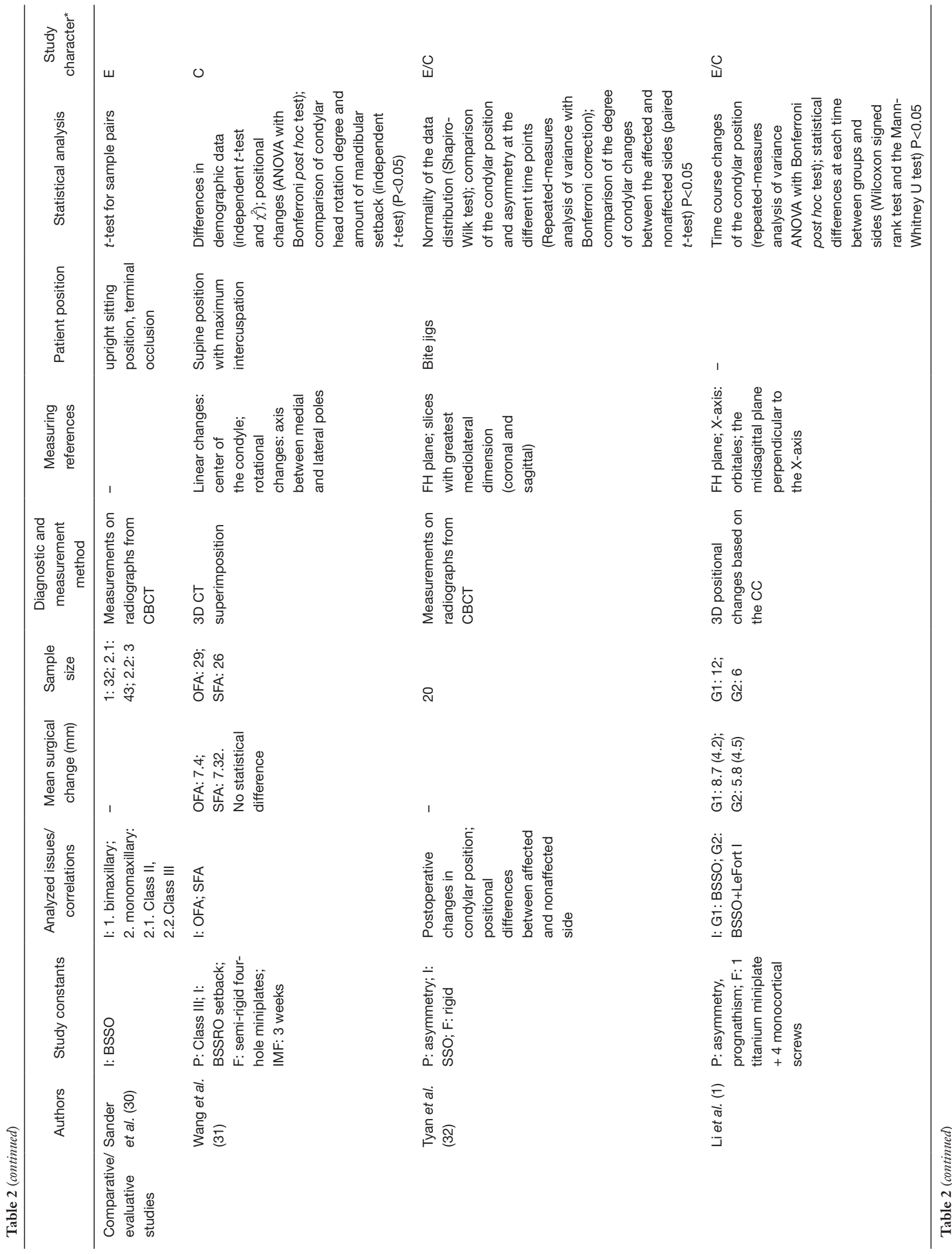




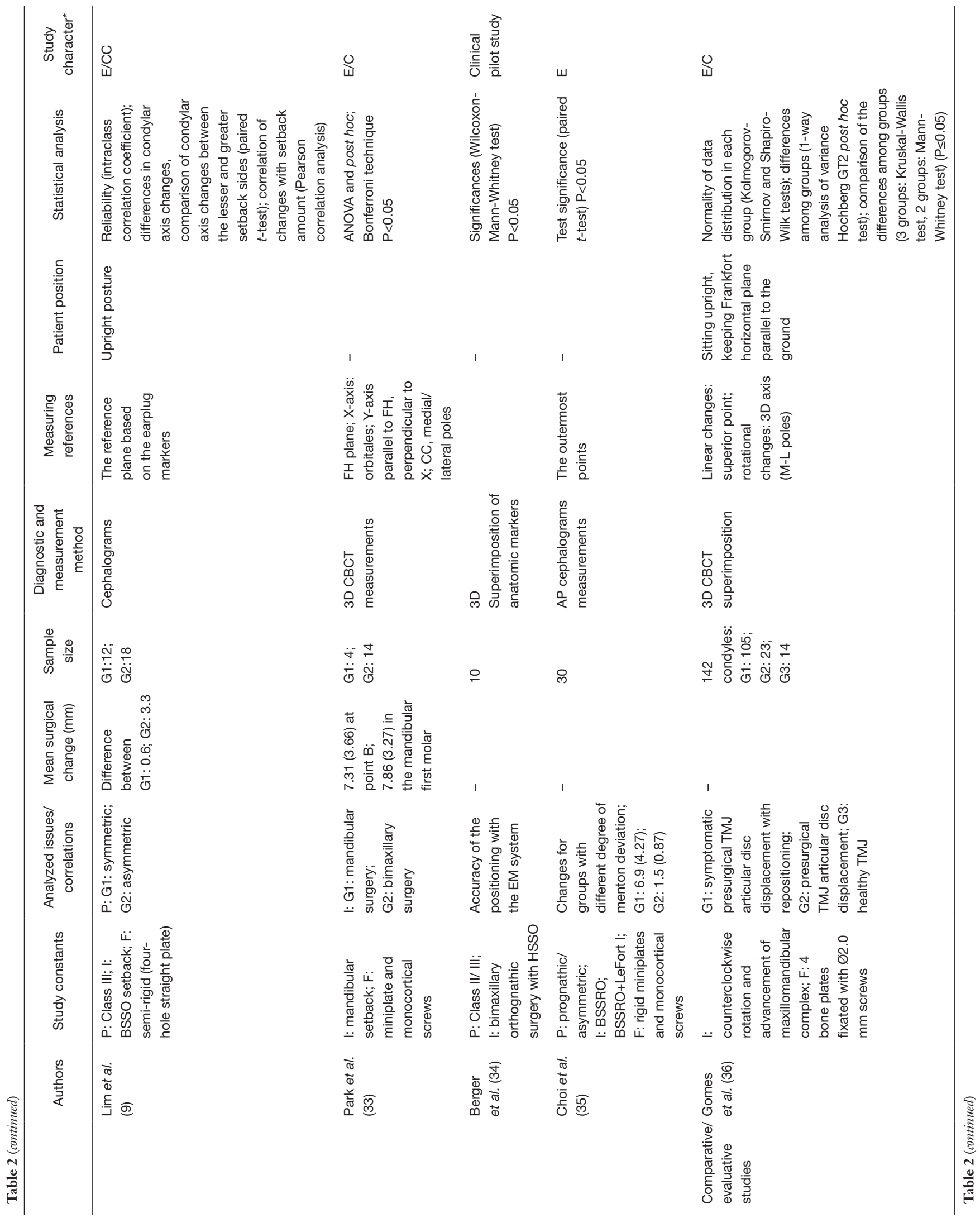




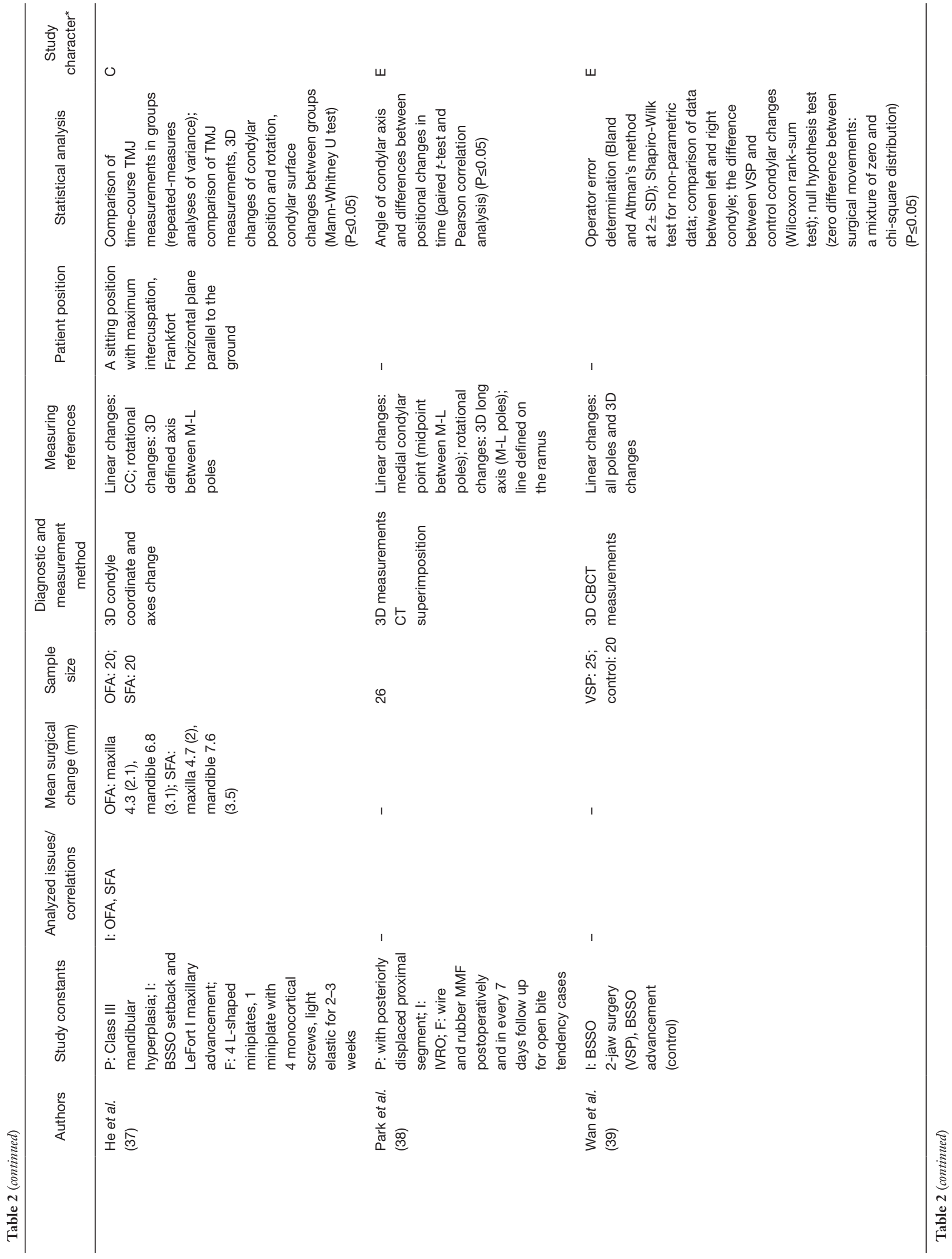




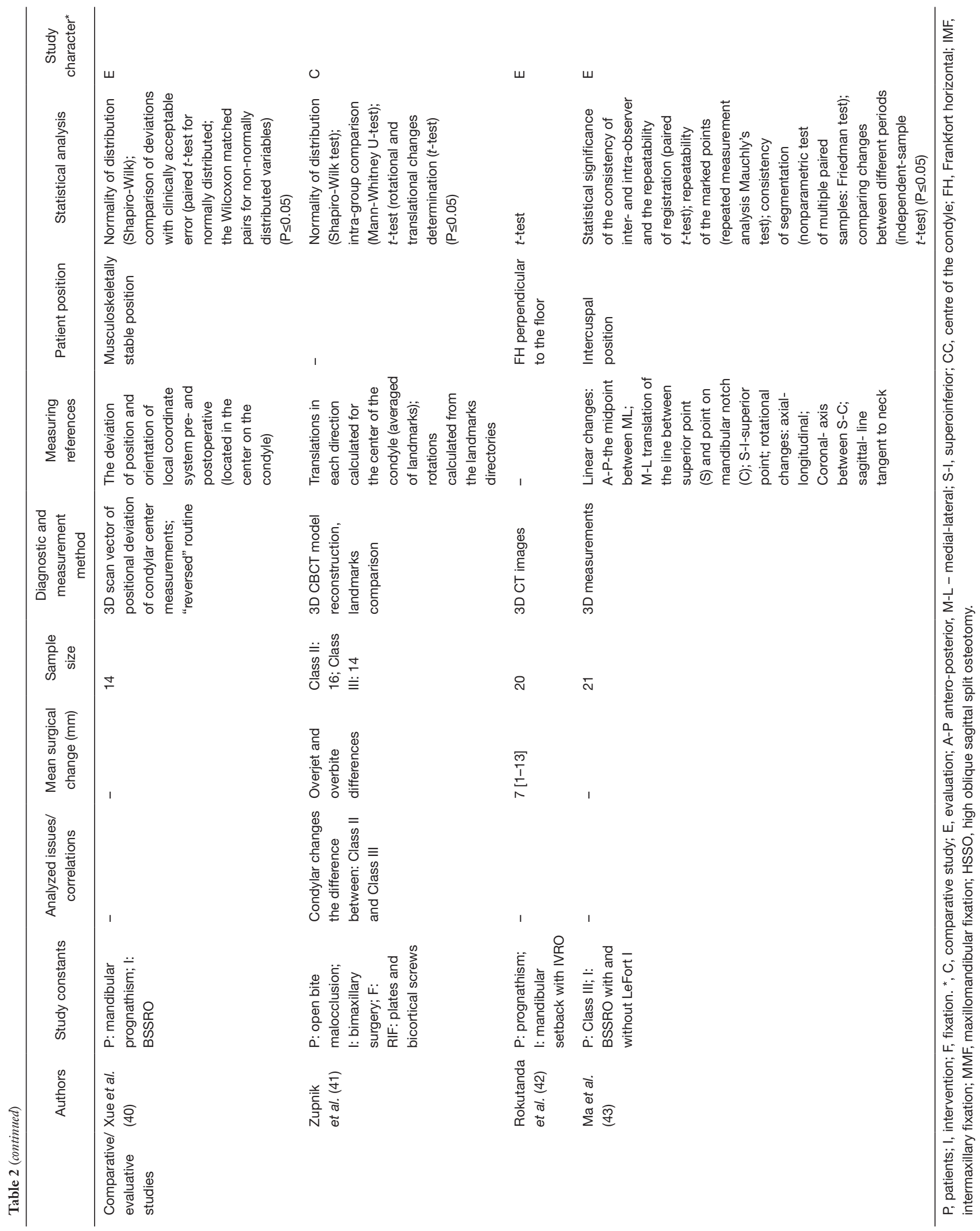




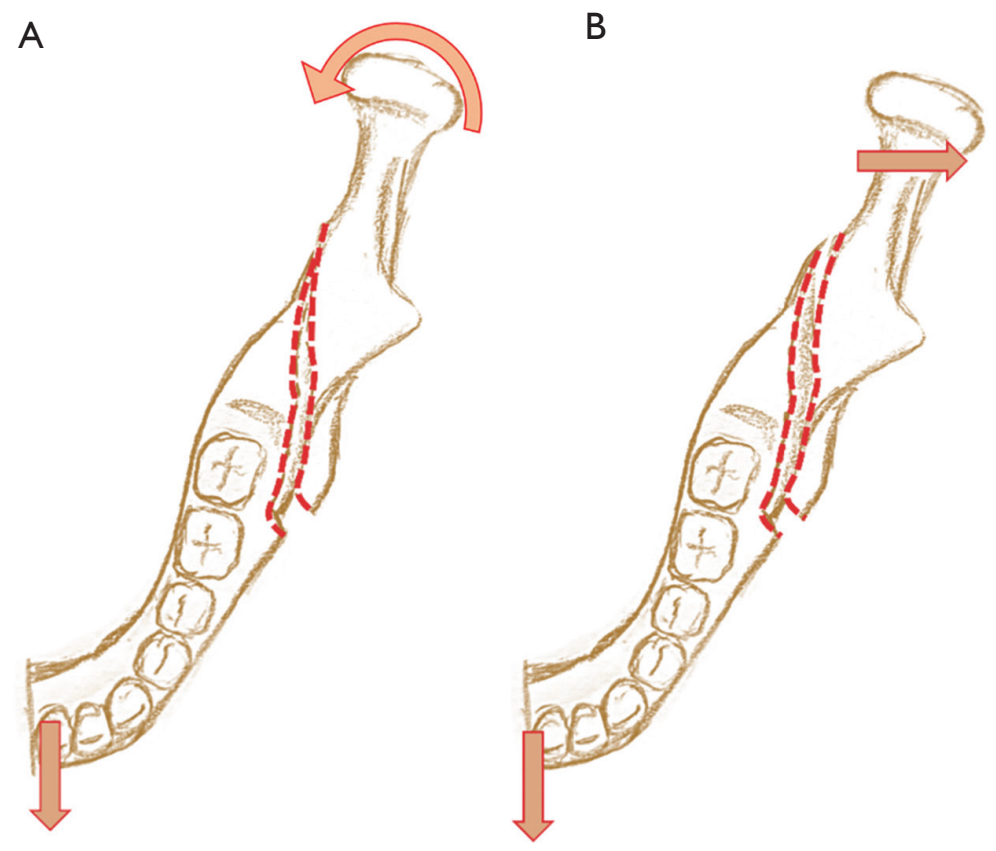

Figure 2 Proximal segment positional change after distal segment advancement: (A) rotation in an axial plane, (B) displacement in a transverse direction.

Varying displacements might also be connected with the greater unilateral tension of soft tissues and muscles, and as a consequence there are unbalanced results $(47,48)$. Kim et al. (29) concluded that the most important factor affecting proximal segment position between deviated and nondeviated sides might not actually be the extent, but the direction of the distal segment movement. Neither the type of malocclusion, nor the menton deviation affect the differences between the sides (29,35). Moreover, the comparison of the sequence of treatments (OFA/SFA), as well as the number of surgical procedures (two-jaw/ single-jaw) did not show significant differences in condylar displacements.

Biomechanically, it seems to be possible to predict specific displacements for individual treatments. Costas et al. (49) claim that all condylar positional rearrangement, despite lateromedial movements, can be predicted. Proximal segments tend to rotate in the coronal plane in the form of passive movement that results from repositioning of the distal segment. This scheme of the displacements is connected with the $\mathrm{V}$ or $\mathrm{U}$ shape of the jaw and the geometry of the osteotomy design. As expected, changes in the position of the condyle, resulting directly from
BSSO, can be considered to be rotations in three axes (Figure $2 A$ ) and lateral-medial translation (Figure 2B). The medial distraction procedure will mainly affect the rotation in the axial plane, as well as ML translation. Correction of mandible asymmetry is connected with much more complex, and difficult to predict positional changes of the proximal segment. Therefore, mandible asymmetry is often considered in the analyses as an excluding criterion. Although condyles undergo complex spatial displacements, translations in the anterior-posterior and inferior-superior directions should not be considered to be the result of the changes introduced to the geometry of the jaw bone itself. They seem to instead be an effect of surgical intervention, such as the positioning of the condyle head in the fossa. In both mentioned directions, the condyle has the greatest natural mobility, as well as an ability to adapt.

Nevertheless, the analysis of the displacements direction and magnitude shows inconsistency among the results. Inward yaw rotation is often reported to be a consequence of mandibular setback $(8,47,50,51)$, while mandibular advancement may result in outward $(21,36)$ or inward (41) rotation. In the correction of Class II and III malocclusions, medial roll was mainly observed $(36,41,52)$. 
The pitch rotation is suspected to be influenced by the direction of distal segment repositioning, and therefore counterclockwise rotation occurs in mandible advancement $(21,36)$, and clockwise rotation occurs in setback $(27)$. The specific pattern for the direction and extent of condylar displacements is difficult to assess. One reason for this may be the adaptation of the proximal to the distal segment, which might depend on the osteotomy method. Greater positional differences can be noticed in the case of the correction of patients with asymmetry defects (1). The tendency of the condyle to return to the preoperative position up to 6 months after surgery was observed in most of the long-term analyses $(1,26,31,35)$.

As a result of orthognathic procedures, changes are introduced to both the bone geometry and the relative position of the craniofacial structures. Displacements of the condyles seem to be inevitable, and changes within some range are considered as clinically insignificant $(29,53)$. The great majority of reported changes were within a clinically acceptable range of $1 \mathrm{~mm}$ and 4 degrees. Nevertheless, even minute change of the condylar position may affect the biomechanics of the system, as well as the functioning of the TMJ. The preoperative functionality of the stomatognathic system is usually regained in 6 months. After that period, full bone union and restoration of occlusal strength can be assumed. Ma et al. (43) noted that the position of the condyle does not change significantly after 3 months of the operation taking place. Nevertheless, biomechanics of the jaw bones may be affected in longer period (late postoperative relapse) by changes in bone morphology associated with bone remodelling and progressive condylar resorption $(5,54)$. Condyle displacement is often mentioned as one of the factors causing skeletal relapse, which might progresses over time even after a 1-year follow-up. Structures such as cartilage and muscle tissue undergo earlier adaptation, but nevertheless still affect long-term results. Differences in the postoperative period displacement values, as well as recovery movement to the original position, may be associated with the tension and further adaptation of soft tissues and muscles $(8,21,47,50)$. During distal segment advancement, tissues are extended, and therefore in the postoperative period they tend to contract, pull the mandible backward, and possibly cause posterior displacement of the condyle.

The positive impact of orthognathic treatment on TMJ problems was noted in the vast majority of publications. Only individual cases of new symptoms and complications were reported $(1,22)$. According to the work of Rokutanda et al. (42), outward yaw rotation and condylar anteroinferior movement can positively affect TMJ problems. Statistically significant rotations in the axial plane are considered as one of the remodeling-inducing factors $(8,47,50)$. Several studies that include considerations of bone remodeling can be found $(8,25,50)$. Ha et al. (50) reported reduced condylar heights on sagittal and coronal planes, as well as resorption on the anterior and superior areas on the sagittal plane, which corroborates with the findings of Park et al. (47). The authors found a correlation between resorption and inward rotation in the axial plane. The pitch rotation of the proximal segment, especially in a counterclockwise direction, is indicated as another factor that has an impact on skeletal relapse $(3,21,55)$. Xi et al. (21) observed that skeletal relapse greater than $2 \mathrm{~mm}$ occurred in 10/11 cases with counterclockwise rotation. The authors also point out the magnitude of advancement, preoperative condylar volume and condyle decrease in volume as potential risk factors affecting skeletal relapse. In later work, the relationship between proximal segment flaring and the risk of condylar volume loss was reported (3). Dicker et al. (20) found that the changes of the proximal segment position affect the direction of masticatory muscles, and therefore also influence the biomechanics of the masticatory system. Mechanical advantage for muscles was noticed, yet the authors did not find significant differences in condyle angular changes, and for this reason do not support the idea of increased condyle loading. They suggest that the condyle can adapt to moderate changes in the sagittal plane due to its plate-like trabecular architecture (56). An et al. (8) also did not find a direct correlation between specific rotation and remodeling. Moreover, bone resorption was observed more frequently than bone formulation. However, a positive relationship between all proximal segment rotations and condylar volume changes was noticed by Yang and Hwang (25). The authors noticed that condylar remodeling and its extent are determined by the direction of condylar displacement during surgery. The exception is a superior surface, on which bone resorption was mostly observed. Prevention of the postoperative structural changes in the TMJ can be obtained by maintaining the condylar head in the center of the articular fossa (57). Ueki et al. (58), on the other hand. claim that the correct positioning of the condyle cannot be definitely determined. The most favourable is the position where the minimal remodelling induced by postoperative biomechanical stress would be the smallest. Short-term analyses are the most commonly found due to the fact that CT scans are usually necessary to depict surgical 


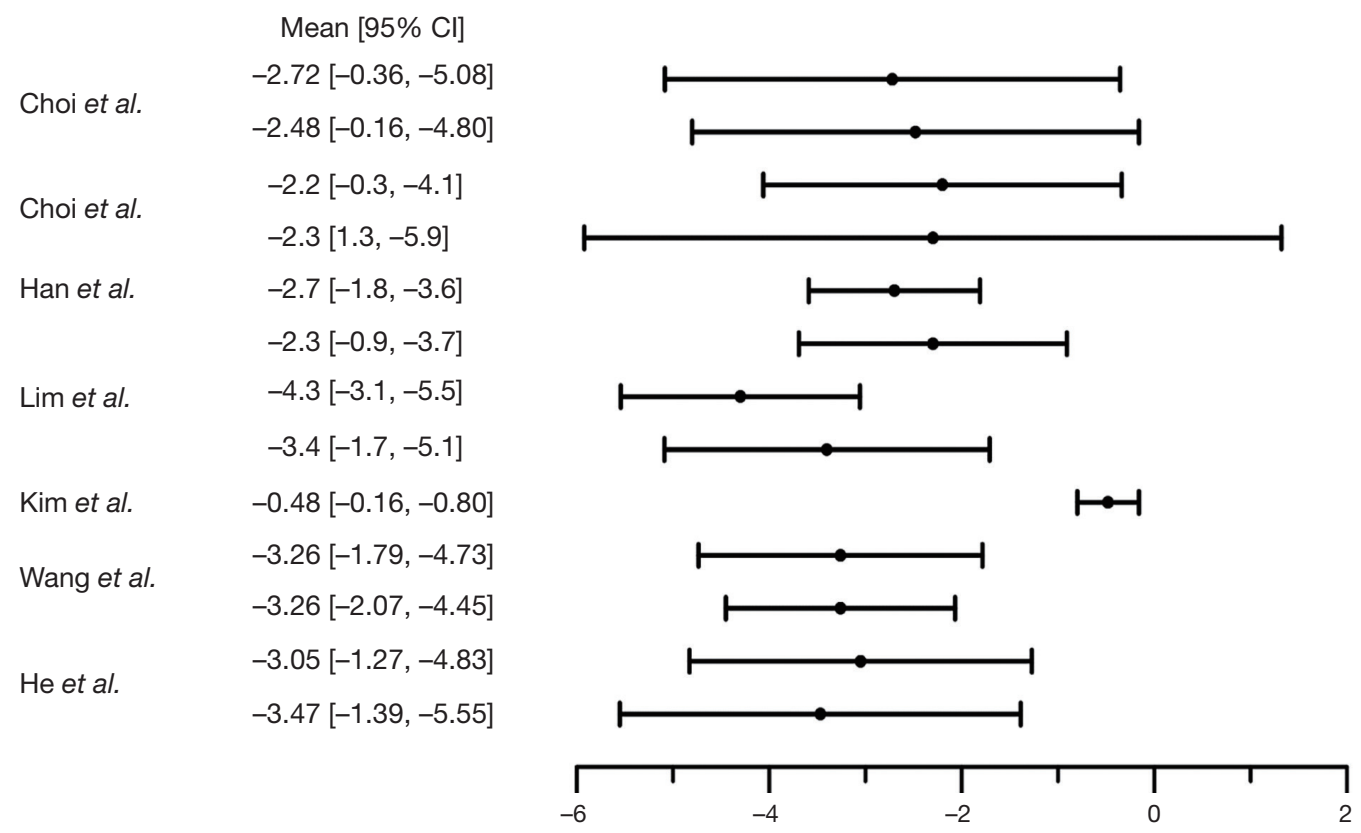

Figure 3 Mean immediate yaw rotation for BSSO/BSSO+LeFort.

changes. Long-term data concerning a statistically sufficient population is more difficult to collect and can explain the lower number of studies presenting these kinds of results. Therefore, the need for long-term analyses was noticed in several publications $(1,26,40,41,58)$. The impact of condyle displacements on changes in the TMJ is still debatable, and what is more the range and importance of those changes, which may be relevant regarding postsurgical normal function, is still unknown (7,30). Global analysis of mean values can be useful in the assessment of the general pattern and range of changes for specific conditions. Among the analyzed articles, in only 7 papers did the inclusion criteria match with regards to the type of defect and the surgical procedure. An exemplary summary for the 13 sample values of immediate changes in yaw rotation are presented in Figure 3. Similar collations of the collected data are included in a low number of data samples. Due to the limited amount of available data and the great heterogeneity of variables between studies, such an assessment poses a demanding task. To estimate the range of displacements, a larger number of studies with a higher level of homogeneity between conditions is needed.

Measurements are still commonly performed on the $2 \mathrm{D}$ radiographs from CBCT scans. They are used in the evaluation of condyle movements, joint space changes, and the intercondylar width and angle. More accurate techniques are based on frequently utilized 3D analyses. $\mathrm{Xi}$ et al. (3) recognize the use of 3D cephalometry on a reconstructed model from CBCT scans for assessing the facial skeleton changes to be the strength of their study. Condyle translational changes are measured as the displacements of the center of the condyle head point, or evaluated from the directions between characteristic points on the head surface. The joint space is measured as the distance between specific landmarks at the opposite surfaces. Ueki et al. (59) claim that condyle positional changes can be reflected by joint space changes. Considering the complexity of condylar displacement, a direct link between both of those values is not fully appropriate, especially when measurements are performed on 2D scans instead of three-dimensional models. The rearrangement of the space between the condylar head of the mandible and the fossa can result from both translational and rotational displacements (Figure 4). Therefore, the reduction of the complex TMJ to a two-dimensional projection, which is especially common in old articles, has obvious limitations (30). Modern methods of analyzing medical images are characterized by additional possibilities of data interpretation and the greater accuracy of measurements. Values presented in articles are given rounded to two decimal places. Such accuracy may be important in the observation of bone remodeling or skeletal relapse, as well as when quantifying complex 

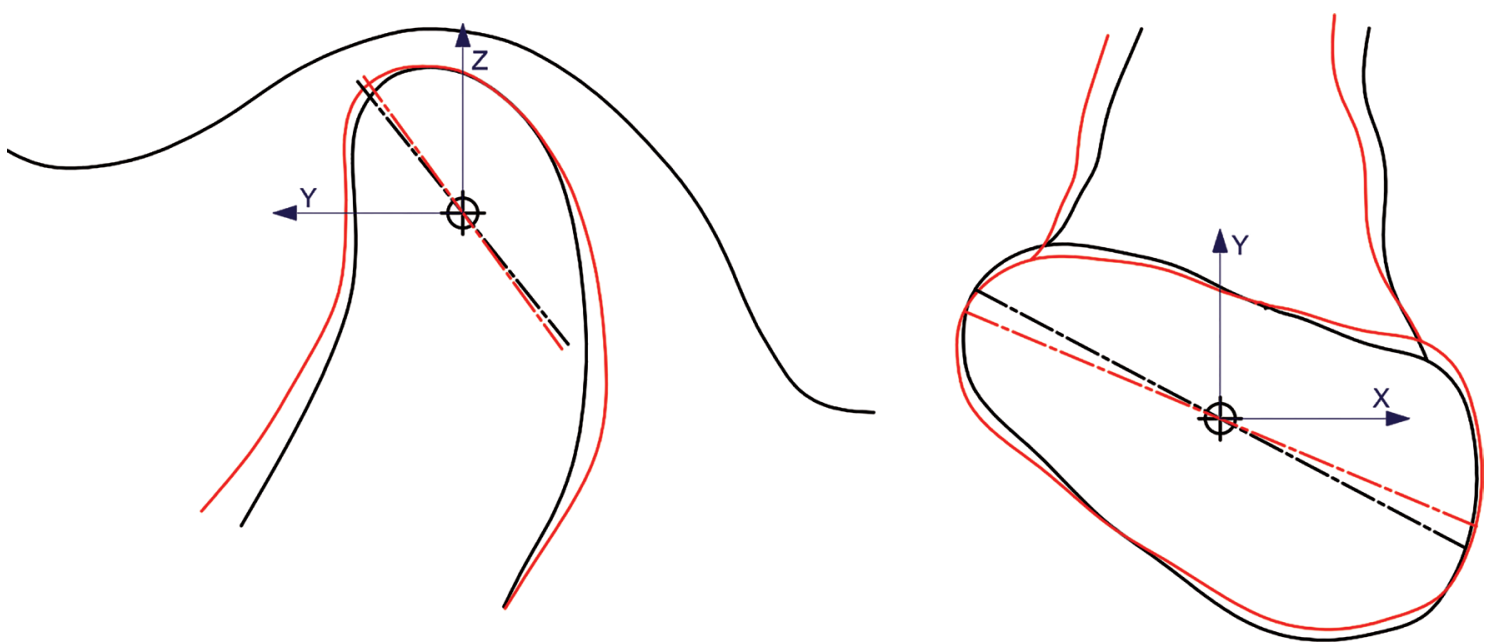

Figure 4 Sagittal and coronal view of positional changes in the joint space resulting from condyle rotation: black—before, red-after condylar axial rotation.

condylar movements. However, conventional 2D and 3D cephalometric analyzes seem to be insufficient to determine such small changes (3). The total measurement error consists of both the errors of the CBCT superimposition and the identification error of the landmarks (60), which are often greater than the accuracy of the reported results. For registration and quantification of such relatively minute movements and bone changes, tools based on $3 \mathrm{D}$ imaging are required (61). Three methods of presenting angular change can be noticed among the studies. In the first, most common method, the mean value of the condyle angular position with SD for treatment periods are reported. This method allows tendency of the angle changes over time to be observed. The mean value of displacements between postoperative intervals can be assessed, however, the range of the angular changes is not possible to define. The second way of reporting condyle rotations is by presenting the average values of the positional changes between specific periods. Theoretically, the values of the lower and the upper limit can be estimated for the given confidence interval using statistical methods.

More recently, innovative computer-aided technologies were introduced into the process of surgery planning and support. The benefits of implementing Virtual Surgery Planning or Electromagnetic navigated systems were noticed, but they do not result in higher accuracy for proximal segment positioning $(34,39)$. The results obtained in advanced computer methods often differ from real surgery, which does not allow for predictions of the treatment outcome (39). Computer simulations are additional techniques that are currently implemented in the research of biological structures. Numerical methods allow for more accurate insight into the results of the procedure on individual structures. Nevertheless, orthognathic surgeries are difficult to recreate using numerical simulation. A reliable outcome would require the reconstruction of complex, manual surgical operations, such as condyle positioning. Quantitative data on changes in the condylar position recorded in clinical measurements could be used as input in numerical simulations. The position of proximal fragments could be directly introduced to the model.

\section{Conclusions}

Quantitative data are often utilized in medical science research for interpretation and analysis. Such considerations can be seen to be valuable for wider evaluations concerning condylar displacement after orthognathic surgeries. Particular attention should therefore be given to both the quantitative and qualitative analysis of this problem. The presented study showed an overview of the issues considering mandibular condyle displacement using a quantitative approach. A great heterogeneity among articles was noticed regarding both the research problem itself and the research methodology. A limited sample size was often reported by authors as a study limitation. The set of results can be useful for interpreting data in 
the form of a meta-analysis. Nevertheless, in such a case, the number of variables between the analyzed articles should be minimized. Due to the complex character of condylar movement, measurements for all rotational and translational directions seem to be appropriate. A lack of data on one of the displacements leads to its influence on the result being neglected. An example of this can be seen to be the least often reported pitch rotation, which was found to be strongly connected with skeletal relapse and changes in TMJ structures. The information available in the literature does not allow conclusions to be drawn regarding the direction and extent of condylar displacements resulting from orthognathic surgeries. More rigorous research concerning yaw and pitch rotation as possible risk factors is suggested. The need for long-term analyses, especially important in studies that include bone remodeling, should also be mentioned. The collected information and quantitative data presented in this overview are believed to be helpful as a source for future comparative analyses, as well as a guide in determining the scientific problem and for conducting research.

\section{Acknowledgments}

This work was carried out during an international internship at the University of Aveiro under the Erasmus+ program. We thank PhD Eng. Andrzej Żak and MSc Eng. Aleksandra Królicka for their useful suggestions and comments on the manuscript.

Funding: None.

\section{Footnote}

Conflicts of Interest: Both authors have completed the ICMJE uniform disclosure form (available at http://dx.doi. org/10.21037/qims-20-677). Dr. DP reports grants from Erasmus+ Program, outside the submitted work. The other author has no conflicts of interest to declare.

Open Access Statement: This is an Open Access article distributed in accordance with the Creative Commons Attribution-NonCommercial-NoDerivs 4.0 International License (CC BY-NC-ND 4.0), which permits the noncommercial replication and distribution of the article with the strict proviso that no changes or edits are made and the original work is properly cited (including links to both the formal publication through the relevant DOI and the license). See: https://creativecommons.org/licenses/by-nc-nd/4.0/.

\section{References}

1. Li J, Ryu SY, Park HJ, Kook MS, Jung S, Han JJ, Oh HK. Changes in condylar position after BSSRO with and without Le Fort I osteotomy via surgery-first approach in mandibular prognathism with facial asymmetry. Oral Surg Oral Med Oral Pathol Oral Radiol 2017;123:661-9.

2. Kim YJ, Oh KM, Hong JS, Lee JH, Kim HM, Reyes $\mathrm{M}$, Cevidanes LH, Park YH. Do patients treated with bimaxillary surgery have more stable condylar positions than those who have undergone single-jaw surgery? J Oral Maxillofac Surg 2012;70:2143-52.

3. Xi T, van Luijn R, Baan F, Schreurs R, de Koning M, Bergé S, Maal T. Three-dimensional analysis of condylar remodeling and skeletal relapse following bimaxillary surgery: A 2-year follow-up study. J Craniomaxillofac Surg 2017;45:1311-8.

4. Hoppenreijs TJM, Maal T, Xi T. Evaluation of Condylar Resorption Before and After Orthognathic Surgery. Semin Orthod 2013;19:106-15.

5. Joss CU, Vassalli IM. Stability After Bilateral Sagittal Split Osteotomy Advancement Surgery With Rigid Internal Fixation: A Systematic Review. J Oral Maxillofac Surg 2009;67:301-13.

6. Cevidanes LH, Bailey LJ, Tucker SF, Styner MA, Mol A, Phillips CL, Proffit WR, Turvey T. Three-dimensional cone-beam computed tomography for assessment of mandibular changes after orthognathic surgery. Am J Orthod Dentofacial Orthop 2007;131:44-50.

7. Carvalho Fde A, Cevidanes LH, da Motta AT, Almeida MA, Phillips C. Three-dimensional assessment of mandibular advancement 1 year after surgery. Am J Orthod Dentofac Orthop 2010;137:S53.e1-12; discussion S53-5.

8. An SB, Park SB, Kim YI, Son WS. Effect of postorthognathic surgery condylar axis changes on condylar morphology as determined by 3-dimensional surface reconstruction. Angle Orthod 2014;84:316-21.

9. Lim SY, Jiang T, Oh MH, Kook MS, Cho JH, Hwang HS. Cone-beam computed tomography evaluation on the changes in condylar long axis according to asymmetric setback in sagittal split ramus osteotomy patients. Angle Orthod 2017;87:254-9.

10. Kalach Mussali AJ, Gonzalez-Magana F, Malagon Hidalgo HO. Correlation between mandibular condylar position and clinical dysfunction index after bilateral sagittal split osteotomies. J Oral Health Craniofac Sci 2019;4:1-7.

11. Prendergast PJ. Finite element models in tissue mechanics and orthopaedic implant design. Clin Biomech (Bristol, 
Avon) 1997;12:343-66.

12. Huiskes R, Chao EY. A survey of finite element analysis in orthopedic biomechanics: The first decade. J Biomech 1983;16:385-409.

13. Shyam Sundar S, Nandlal B, Saikrishna D, Mallesh G. Finite Element Analysis: A Maxillofacial Surgeon's Perspective. J Maxillofac Oral Surg 2012;11:206-11.

14. Brodland GW. Finite Element Methods for Developmental Biology. Int Rev Cytol 1994;150:95-118.

15. Savoldelli C, Bouchard PO, Manière-Ezvan A, Bettega G, Tillier Y. Comparison of stress distribution in the temporomandibular joint during jaw closing before and after symphyseal distraction: A finite element study. Int J Oral Maxillofac Surg 2012;41:1474-82.

16. Dai Z, Hou M, Ma W, Song DL, Zhang CX, Zhou WY. Evaluation of the Transverse Displacement of the Proximal Segment After Bilateral Sagittal Split Ramus Osteotomy With Different Lingual Split Patterns and Advancement Amounts Using the Finite Element Method. J Oral Maxillofac Surg 2016;74:2286.e1-2286.e11.

17. Liu Z, Shu J, Zhang Y, Fan Y. The Biomechanical Effects of Sagittal Split Ramus Osteotomy on Temporomandibular Joint. Comput Methods Biomech Biomed Engin 2018;21:617-24.

18. Xia JJ, Shevchenko L, Gateno J, Teichgraeber JF, Taylor TD, Lasky RE, English JD, Kau CH, McGrory KR. Outcome study of computer-aided surgical simulation in the treatment of patients with craniomaxillofacial deformities. J Oral Maxillofac Surg 2011;69:2014-24.

19. Aboul-Hosn Centenero S, Hernández-Alfaro F. 3D planning in orthognathic surgery: CAD/CAM surgical splints and prediction of the soft and hard tissues results - Our experience in 16 cases. J Craniomaxillofac Surg 2012;40:162-8.

20. Dicker GJ, Tuijt M, Koolstra JH, Van Schijndel RA, Castelijns JA, Tuinzing DB. Static and dynamic loading of mandibular condyles and their positional changes after bilateral sagittal split advancement osteotomies. Int J Oral Maxillofac Surg 2012;41:1131-6.

21. Xi T, Maal T, de Koning M, Bergé S, Hoppenreijs T, Maal T. The role of mandibular proximal segment rotations on skeletal relapse and condylar remodelling following bilateral sagittal split advancement osteotomies. J Craniomaxillofac Surg 2015;43:1716-22.

22. Han YS, Jung YE, Song IS, Lee SJ, Seo BM. ThreeDimensional Computed Tomographic Assessment of Temporomandibular Joint Stability After Orthognathic Surgery. J Oral Maxillofac Surg 2016;74:1454-62.
23. Gomes LR, Cevidanes LH, Gomes MR, Ruellas AC, Ryan DP, Paniagua B, Wolford LM, Gonçalves JR. Counterclockwise maxillomandibular advancement surgery and disc repositioning: can condylar remodeling in the long-term follow-up be predicted? Int J Oral Maxillofac Surg 2017;46:1569-78.

24. Hwang HS, Jiang T, Sun L, Lee KM, Oh MH, Biao Y, Oh HK, Bechtold TE. Condylar head remodeling compensating for condylar head displacement by orthognathic surgery. J Craniomaxillofac Surg 2019;47:406-13.

25. Yang HJ, Hwang SJ. Change in condylar position in posterior bending osteotomy minimizing condylar torque in BSSRO for facial asymmetry. J Craniomaxillofac Surg 2014;42:325-32.

26. Choi BJ, Choi YH, Lee BS, Kwon YD, Choo YJ, Ohe JY. A CBCT study on positional change in mandibular condyle according to metallic anchorage methods in skeletal class III patients after orthognatic surgery. J Craniomaxillofac Surg 2014;42:1617-22.

27. Kim HM, Baek SH, Kim TY, Choi JY. Evaluation of three-dimensional position change of the condylar head after orthognathic surgery using computer-aided design/ computer-aided manufacturing-made condyle positioning jig. J Craniofac Surg 2014;25:2002-7.

28. Han JJ, Hwang SJ. Three-dimensional analysis of postoperative returning movement of perioperative condylar displacement after bilateral sagittal split ramus osteotomy for mandibular setback with different fixation methods. J Craniomaxillofac Surg 2015;43:1918-25.

29. Kim JW, Son WS, Kim SS, Kim YI. Proximal Segment Changes After Bilateral Sagittal Split Ramus Osteotomy in Facial Asymmetry Patients. J Oral Maxillofac Surg 2015;73:1592-605.

30. Sander AK, Martini M, Konermann AC, Meyer U, Wenghoefer M. Freehand condyle-positioning during orthognathic surgery: Postoperative cone-beam computed tomography shows only minor morphometric alterations of the temporomandibular joint position. J Craniofac Surg 2015;26:1471-6.

31. Wang T, Han JJ, Oh HK, Park HJ, Jung S, Kook MS. Comparison of Orthodontics-First and Surgery-First Approach in Positional Changes of the Condyle After Mandibular Setback Surgery Using Three-Dimensional Analysis. J Oral Maxillofac Surg 2016;74:2487-96.

32. Tyan S, Kim HH, Park KH, Kim SJ, Kim KA, Ahn HW. Sequential changes of postoperative condylar position in patients with facial asymmetry. Angle Orthod 
2017;87:260-8.

33. Park JC, Kim UK, Hwang DS. Three-dimensional analysis of perioperative condylar displacement after mandibular setback surgery with intended manual condylar positioning. J Craniofac Surg 2018;29:e767-e773.

34. Berger M, Nova I, Kallus S, Ristow O, Eisenmann U, Dickhaus H, Engel M, Freudlsperger C, Hoffmann J, Seeberger R. Electromagnetic navigated condylar positioning after high oblique sagittal split osteotomy of the mandible: a guided method to attain pristine temporomandibular joint conditions. Oral Surg Oral Med Oral Pathol Oral Radiol 2018;125:407-414.e1.

35. Choi BJ, Kim BS, Lim JM, Jung J, Lee JW, Ohe JY. Positional change in mandibular condyle in facial asymmetric patients after orthognathic surgery: cone-beam computed tomography study. Maxillofac Plast Reconstr Surg 2018;40:13.

36. Gomes LR, Soares Cevidanes LH, Gomes MR, Carlos de Oliveira Ruellas A, Obelenis Ryan DP, Paniagua B, Wolford LM, Gonçalves JR. Three-dimensional quantitative assessment of surgical stability and condylar displacement changes after counterclockwise maxillomandibular advancement surgery: Effect of simultaneous articular disc repositioning. Am J Orthod Dentofacial Orthop 2018;154:221-33.

37. He X, He J, Yuan H, Chen W, Jiang H, Cheng J. SurgeryFirst and Orthodontic-First Approaches Produce Similar Patterns of Condylar Displacement and Remodeling in Patients With Skeletal Class III Malocclusion. J Oral Maxillofac Surg 2019;77:1446-56.

38. Park JC, Lee J, Lim HJ, Kim BC. Rotation tendency of the posteriorly displaced proximal segment after vertical ramus osteotomy. J Craniomaxillofac Surg 2018;46:2096-102.

39. Wan Y, Jackson T, Chung C, Gao F, Blakey G, Nguyen T. Comparison of condylar position in orthognathic surgery cases treated with virtual surgical planning vs . conventional model planning. Orthod Craniofac Res 2019;22 Suppl 1:142-8.

40. Xue C, Tian Y, Wang L, Yang X, Luo E, Bai D. Surgical guide and $\mathrm{CAD} / \mathrm{CAM}$ prebent titanium plate for sagittal split ramus osteotomy in the correction of mandibular prognathism. Br J Oral Maxillofac Surg 2018;56:586-93.

41. Zupnik JT, Ioshida M, Yatabe M, Ruellas ACO, Gomes LR, Aronovich S, Benavides E, Edwards SP, Paniagua B, Cevidanes LHS. Three-dimensional analysis of condylar changes in surgical correction for open bite patients with skeletal class II and class III malocclusions. Int J Oral Maxillofac Surg 2019;48:739-45.
42. Rokutanda S, Yamada SI, Yanamoto S, Sakamoto H, Morita Y, Rokutanda H, Kohara H, Yoshimatsu M, Yoshimi T, Nakamura T, Ino-Kondo A, Moriuchi E, Umeda M. Effects of the changes in the condylar long axis angle and condylar position on temporomandibular symptoms after intraoral vertical ramus osteotomy : a preliminary study. Oral Surg Oral Med Oral Pathol Oral Radiol 2019;128:597-605.

43. Ma RH, Li G, Yin S, Sun Y, Li Z, Ma XC. Quantitative assessment of condyle positional changes before and after orthognathic surgery based on fused 3D images from cone beam computed tomography. Clin Oral Investig 2020;24:2663-72.

44. Gunson MJ, Arnett GW, Milam SB. Pathophysiology and pharmacologic control of osseous mandibular condylar resorption. J Oral Maxillofac Surg 2012;70:1918-34.

45. Wolford LM, Reiche-Fischel O, Mehra P. Changes in temporomandibular joint dysfunction after orthognathic surgery. J Oral Maxillofac Surg 2003;61:655-60; discussion 661.

46. Baek SH, Kim TK, Kim MJ. Is there any difference in the condylar position and angulation after asymmetric mandibular setback? Oral Surg Oral Med Oral Pathol Oral Radiol Endod 2006;101:155-63.

47. Park SB, Yang YM, Kim YI, Cho BH, Jung YH, Hwang DS. Effect of bimaxillary surgery on adaptive condylar head remodeling: Metric analysis and image interpretation using cone-beam computed tomography volume superimposition. J Oral Maxillofac Surg 2012;70:1951-9.

48. Ueki K, Marukawa K, Nakagawa K, Yamamoto E. Condylar and temporomandibular joint disc positions after mandibular osteotomy for prognathism. J Oral Maxillofac Surg 2002;60:1424-32; discussion 1432-4.

49. Costas A, Sanromán JF, Castro P, Ferro MF, Lopez A, Stavaru B. Study of condylar positional changes after sagittal split osteotomy for mandibular advancement: A prospective cohort study. J Craniomaxillofac Surg 2018;46:1079-90.

50. Ha MH, Kim YI, Park SB, Kim SS, Son WS. Conebeam computed tomographic evaluation of the condylar remodeling occurring after mandibular set-back by bilateral sagittal split ramus osteotomy and rigid fixation. Korean J Orthod 2013;43:263-70.

51. Roh YC, Shin SH, Kim SS, Sandor GK, Kim YD. Skeletal stability and condylar position related to fixation method following mandibular setback with bilateral sagittal split ramus osteotomy. J Craniomaxillofac Surg 2014;42:1958-63.

52. Goncalves JR, Wolford LM, Cassano DS, da Porciuncula 
G, Paniagua B, Cevidanes LH. Temporomandibular joint condylar changes following maxillomandibular advancement and articular disc repositioning. J Oral Maxillofac Surg 2013;71:1759.e1-15.

53. Kim JW, Kim JC, Cheon KJ, Cho SW, Kim YH, Yang BE. Computer-Aided Surgical Simulation for Yaw Control of the Mandibular Condyle and Its Actual Application to Orthognathic Surgery: A One-Year Follow-Up Study. Int J Environ Res Public Health 2018;15:2380.

54. Hoppenreijs TJ, Stoelinga PJ, Grace KL, Robben CM. Long-term evaluation of patients with progressive condylar resorption following orthognathic surgery. Int J Oral Maxillofac Surg 1999;28:411-8.

55. Jung J, Kim JH, Lee JW, Ohe JY, Choi BJ. Threedimensional volumetric analysis of condylar head and glenoid cavity after mandibular advancement. J Craniomaxillofac Surg 2018;46:1470-5.

56. Giesen EB, Van Eijden TM. The three-dimensional cancellous bone architecture of the human mandibular condyle. J Dent Res 2000;79:957-63.

57. Saka B, Petsch I, Hingst V, Härtel J. The influence of pre- and intraoperative positioning of the condyle in the

Cite this article as: Pachnicz D, Ramos A. Mandibular condyle displacements after orthognathic surgery-an overview of quantitative studies. Quant Imaging Med Surg 2021;11(4):16281650. doi: $10.21037 /$ qims-20-677 centre of the articular fossa on the position of the disc in orthognathic surgery. A magnetic resonance study. Br J Oral Maxillofac Surg 2004;42:120-6.

58. Ueki K, Moroi A, Sotobori M, Ishihara Y, Marukawa K, Takatsuka S, Yoshizawa K, Kato K, Kawashiri S. A hypothesis on the desired postoperative position of the condyle in orthognathic surgery: a review. Oral Surg Oral Med Oral Pathol Oral Radiol 2012;114:567-76.

59. Ueki K, Moroi A, Tsutsui T, Hiraide R, Takayama A, Saito Y, Sato M, Baba N, Tsunoda T, Hotta A, Yoshizawa K. Time-course change in temporomandibular joint space after advancement and setback mandibular osteotomy with Le Fort I osteotomy. J Craniomaxillofac Surg 2018;46:679-87.

60. de Oliveira AE, Cevidanes LH, Phillips C, Motta A, Burke B, Tyndall D. Observer reliability of three-dimensional cephalometric landmark identification on cone-beam computerized tomography. Oral Surg Oral Med Oral Pathol Oral Radiol Endod 2009;107:256-65.

61. Baan F, Liebregts J, Xi T, Schreurs R, de Koning M, Bergé S, Maal T. A new 3D tool for assessing the accuracy of bimaxillary surgery: The OrthoGnathicanAlyser. PLoS One 2016;11:e0149625. 


\begin{tabular}{|c|c|c|c|c|c|c|c|c|c|c|c|c|c|c|c|c|c|c|}
\hline \multirow{3}{*}{ Author, year } & \multicolumn{18}{|c|}{ Immediate } \\
\hline & \multicolumn{3}{|c|}{ Yaw [ ["] } & \multicolumn{3}{|c|}{ Roll ["] } & \multicolumn{3}{|c|}{ Pitch ["] } & \multicolumn{3}{|c|}{ Mediolateral [mm] } & \multicolumn{3}{|c|}{ Anteroposterior [mm] } & \multicolumn{3}{|c|}{ Superoinferior $[\mathrm{mm}]$} \\
\hline & Mean (SD) & Max & Min & Mean (SD) & Max & Min & Mean (SD) & $\operatorname{Max}$ & Min & Mean (SD) & $\operatorname{Max}$ & Min & Mean (SD) & $\operatorname{Max}$ & Min & Mean (SD) & $\operatorname{Max}$ & $\operatorname{Min}$ \\
\hline \multirow[t]{3}{*}{ Gomes et al. (36) } & $4.0(5.5)$ & 18.3 & -11.8 & $-5.5(6.6)$ & 8.7 & -30.5 & $-7.7(7.6)$ & 14.0 & -32.3 & $-1.5(1.7)$ & 2.5 & -7.3 & $-0.6(1.2)$ & 3.2 & -3.5 & $-0.9(1.2)$ & 2.3 & -5.0 \\
\hline & $3.2(5.1)$ & 12.1 & -10.6 & $-2.4(5.4)$ & 6.1 & -13.5 & $-3.3(5.5)$ & 7.9 & -18.6 & $-1.0(1.4)$ & 1.4 & -4.8 & $-0.7(0.7)$ & 1.0 & -2.4 & $0.1(0.8)$ & 1.2 & -1.9 \\
\hline & $3.8(5.1)$ & 11.6 & -5.0 & $-0.3(5.3)$ & 8.9 & -12.3 & $-1.4(4.6)$ & 10.7 & -8.5 & $-0.9(1.3)$ & 1.1 & -2.6 & $-0.9(1.1)$ & 0.4 & -3.2 & $0.3(0.9)$ & 0.4 & -3.2 \\
\hline Gomes et al. (23) & $4.5(6.0)$ & 18.3 & -11.8 & $-5.2(7.3)$ & 8.7 & -30.5 & $-7.5(8.0)$ & 14 & -32.3 & $-1.5(1.8)$ & 2.5 & -7.3 & $-0.6(1.3)$ & 3.2 & -3.5 & $-1.0(1.3)$ & 2.3 & -5.0 \\
\hline \multirow[t]{5}{*}{ Xue et al. (40) } & 0.64 & 1.10 & 0.17 & 2.25 & 5.26 & 0.07 & 1.03 & 1.88 & 0.88 & -0.46 & -0.02 & -1.01 & 0.32 & 0.93 & 0.06 & 0.46 & 0.67 & 0.12 \\
\hline & 0.34 & 0.63 & 0.18 & 2.25 & 5.84 & 0.09 & 0.86 & 2.42 & 0.10 & -0.53 & -0.01 & -1.04 & 0.51 & 1.35 & 0.06 & 0.61 & 1.13 & 0.03 \\
\hline & -3.85 & -0.68 & -4.45 & -1.13 & -0.06 & -3.39 & -2.69 & -0.76 & -6.19 & 0.76 & 1.83 & 0.04 & -0.47 & -0.06 & -0.72 & -0.54 & -0.09 & -1.41 \\
\hline & -3.00 & -0.63 & -8.16 & -1.14 & 0.08 & -1.80 & -0.58 & -0.02 & -1.50 & 0.74 & 1.99 & 0.01 & -0.41 & -0.01 & -1.15 & -0.49 & -0.05 & -1.43 \\
\hline & Mean (SD) & $\operatorname{Max}^{\dagger}$ & $\operatorname{Min}^{ \pm}$ & Mean (SD) & $\operatorname{Max}^{\dagger}$ & $\operatorname{Min}^{+}$ & Mean (SD) & $\operatorname{Max}^{\dagger}$ & $\operatorname{Min}^{\ddagger}$ & Mean (SD) & $\operatorname{Max}^{\dagger}$ & $\operatorname{Min}^{ \pm}$ & Mean (SD) & $\operatorname{Max}^{\dagger}$ & $\operatorname{Min}^{\ddagger}$ & Mean (SD) & $\operatorname{Max}^{\dagger}$ & $\operatorname{Min}^{7}$ \\
\hline \multirow[t]{2}{*}{ He et al. (37) } & $-3.47(4.45)$ & -2.05 & -4.89 & $0.13(4.13)$ & 1.45 & -1.19 & $2.24(13.16)$ & 6.45 & -1.97 & $0.79(1.34)$ & 1.22 & 0.36 & $-0.10(0.78)$ & 0.15 & -0.35 & $-0.68(1.32)$ & -0.26 & -1.10 \\
\hline & $-3.05(3.8)$ & -1.95 & -4.15 & $-0.67(2.52)$ & 0.06 & -1.40 & $1.38(9.79)$ & 4.22 & -1.46 & $0.67(0.87)$ & 0.92 & 0.42 & $0.19(0.45)$ & 0.32 & 0.06 & $-0.33(0.60)$ & -0.16 & -0.50 \\
\hline \multirow[t]{2}{*}{ Park et al. (38) } & $-0.18(3.84)$ & 1.25 & -1.61 & $-4.57(7.8)$ & -1.66 & -7.48 & $3.43(6.47)$ & 5.85 & 1.01 & $-0.76(0.97)$ & -0.40 & -1.12 & $1.23(1.79)$ & 1.90 & 0.56 & $-2.63(1.54)$ & -2.05 & -3.21 \\
\hline & $-1.66(7.1)$ & 1.49 & -4.81 & $-6.62(4.7)$ & -4.54 & -8.70 & $5.09(7.14)$ & 8.26 & 1.92 & $-0.76(1.34)$ & -0.17 & -1.35 & $1.14(1.35)$ & 1.74 & 0.54 & $-1.93(1.9)$ & -1.09 & -2.77 \\
\hline \multirow[t]{2}{*}{ Wang et al. (31) } & $-3.26(3.13)$ & -2.44 & -4.08 & $-0.3(3.25)$ & 0.55 & -1.15 & $4.08(13.25)$ & 7.56 & 0.60 & $0.65(0.95)$ & 0.9 & 0.4 & $-0.03(0.64)$ & 0.14 & -0.20 & $-0.65(0.90)$ & -0.41 & -0.89 \\
\hline & $-3.26(3.65)$ & -2.24 & -4.28 & $0.86(4.22)$ & 2.03 & -0.31 & $0.5(18.17)$ & 5.56 & -4.56 & $0.56(0.71)$ & 0.76 & 0.36 & $-0.09(0.77)$ & 0.12 & -0.30 & $-0.64(0.93)$ & -0.38 & -0.90 \\
\hline Kim et al. (27) & $-0.48(1.00)$ & -0.16 & -0.80 & $-0.04(0.91)$ & 0.25 & -0.33 & $-0.21(0.97)$ & 0.10 & -0.52 & $0.41(0.74)$ & 0.65 & 0.17 & $-0.09(0.51)$ & 0.07 & -0.25 & $0.14(0.38)$ & 0.26 & 0.02 \\
\hline \multirow[t]{2}{*}{ Wan et al. $(39)^{\S}$} & - & 14.27 & 0.71 & - & 19.82 & 0.75 & - & $116.16(28.29)$ & 0.39 & - & 3.79 & 0 & - & 3.48 & 0 & - & 2.79 & 0.05 \\
\hline & \multicolumn{18}{|c|}{6 weeks } \\
\hline Author, year & & Yaw ["] & & & Roll ["] & & & Pitch [ $\left.{ }^{[}\right]$ & & & iolateral & & & oposterio & & & roinferior & \\
\hline & Mean (SD) & $\operatorname{Max}^{+}$ & $\operatorname{Min}^{\ddagger}$ & Mean (SD) & $\operatorname{Max}^{+}$ & $\operatorname{Min}^{+}$ & Mean (SD) & $\operatorname{Max}^{\dagger}$ & $\operatorname{Min}^{\ddagger}$ & Mean (SD) & $\operatorname{Max}^{\dagger}$ & $\operatorname{Min}^{\ddagger}$ & Mean (SD) & $\operatorname{Max}^{+}$ & $\operatorname{Min}^{\ddagger}$ & Mean (SD) & $\operatorname{Max}^{+}$ & $\operatorname{Min}^{\ddagger}$ \\
\hline Zupnik et al. (41) & $-7.55(6.33)$ & -5.27 & -9.83 & $5.58(3.61)$ & 6.88 & 4.28 & $-3.22(2.23)$ & -2.42 & -4.02 & $-0.88(0.6)$ & -0.66 & -1.10 & $1.02(1.11)$ & 1.42 & 0.62 & $-0.58(0.4)$ & -0.44 & -0.72 \\
\hline & $-5.41(3.07)$ & -4.22 & -6.60 & $4.63(2.35)$ & 5.54 & 3.72 & $-2.30(1.27)$ & -1.81 & -2.79 & $-0.6(0.47)$ & -0.42 & -0.78 & $0.5(0.47)$ & 0.68 & 0.32 & $-0.3(0.31)$ & -0.18 & -0.42 \\
\hline & $3.05(3.17)$ & 4.19 & 1.91 & $-2.50(3.81)$ & -1.13 & -3.87 & $6.07(5.15)$ & 7.93 & 4.21 & $1.30(1.30)$ & 1.77 & 0.83 & $-1.23(1.32)$ & -0.75 & -1.71 & $0.94(0.80)$ & 1.23 & 0.65 \\
\hline & $0.95(0.78)$ & 1.25 & 0.65 & $-2.07(1.77)$ & -1.38 & -2.76 & $2.47(1.79)$ & 3.16 & 1.78 & $0.26(0.33)$ & 0.39 & 0.13 & $-0.47(0.32)$ & -0.35 & -0.59 & $0.7(0.79)$ & 1.01 & 0.39 \\
\hline & & & & & & & & & & & & & & & & & & \\
\hline Author, year & & Yaw [ $\left.{ }^{\circ}\right]$ & & & Roll ["] & & & Pitch ["] & & & iolateral & & & oposterio & & & roinferior & \\
\hline & Mean (SD) & Max & Min & Mean (SD) & $\operatorname{Max}$ & Min & Mean (SD) & $\operatorname{Max}$ & Min & Mean (SD) & $\operatorname{Max}$ & Min & Mean (SD) & Max & Min & Mean (SD) & $\operatorname{Max}$ & Min \\
\hline Han et al. (22) & $2.7(2.0)$ & 6.2 & 0.5 & $2.4(2.0)$ & 7.8 & 0.1 & $3.6(2.3)$ & 9.8 & 0.1 & $0.3(0.2)$ & 0.9 & 0.02 & $0.4(0.6)$ & 3.8 & 0.0 & $0.3(0.2)$ & 0.7 & 0.1 \\
\hline & $-3.4(2.9)$ & -0.2 & -13.1 & $-2.7(1.8)$ & -0.6 & -8.7 & $-4.4(5.9)$ & -0.8 & -23.8 & $-0.7(0.7)$ & 0.0 & -4.84 & $-0.3(0.2)$ & -0.0 & -1.3 & $-0.6(0.6)$ & 0.0 & -3.2 \\
\hline Ma et al. (43) & $-4.14(3.70)$ & -2.98 & -5.29 & $-1.49(1.92)$ & -0.89 & -2.08 & $0.95(2.88)$ & 1.85 & 0.05 & $-0.06(0.65)$ & 0.14 & -0.27 & $0.02(0.51)$ & 0.17 & -0.13 & $0.06(0.41)$ & 0.19 & -0.07 \\
\hline & & & & & & & & & & & & & & & & & & \\
\hline Author. year & & Yaw ["] & & & Roll ["] & & & Pitch [ $\left.{ }^{\circ}\right]$ & & & iolateral & & & oposterio & & & roinferior & \\
\hline & Mean (SD) & Max & Min & Mean (SD) & $\operatorname{Max}$ & Min & Mean (SD) & $\operatorname{Max}$ & Min & Mean (SD) & $\operatorname{Max}$ & Min & Mean (SD) & Max & Min & Mean (SD) & $\operatorname{Max}$ & Min \\
\hline Ma et al. (43) & $-4.1(3.86)$ & -2.90 & -5.31 & $-1.3(2.21)$ & -0.61 & -1.99 & $0.78(3.13)$ & 1.76 & -0.19 & $-0.05(0.64)$ & 0.49 & -0.25 & $0.09(0.48)$ & 0.23 & -0.07 & $-0.12(0.38)$ & -0.01 & -0.24 \\
\hline & Mean (SD) & $\operatorname{Max}^{\dagger}$ & $\operatorname{Min}^{ \pm}$ & Mean (SD) & $\operatorname{Max}^{\dagger}$ & $\operatorname{Min}^{+}$ & Mean (SD) & $\operatorname{Max}^{\dagger}$ & $\operatorname{Min}^{\ddagger}$ & Mean (SD) & $\operatorname{Max}^{\dagger}$ & $\operatorname{Min}^{\ddagger}$ & Mean (SD) & $\operatorname{Max}^{\dagger}$ & $\operatorname{Min}^{\ddagger}$ & Mean (SD) & $\operatorname{Max}^{\dagger}$ & $\operatorname{Min}^{\ddagger}$ \\
\hline Wang et al. (31) & $-1.98(3.1)$ & -1.16 & -2.80 & $-0.19(2.92)$ & 0.58 & -0.96 & $2.02(12.78)$ & 5.38 & -1.34 & $0.03(1.48)$ & 0.42 & -0.36 & $0.30(0.83)$ & 0.52 & 0.08 & $-0.22(0.92)$ & 0.02 & -0.46 \\
\hline & $-2.22(3.18)$ & -1.33 & -3.11 & $1.02(4.07)$ & 2.15 & -0.11 & $-1.34(19.7)$ & 4.14 & -6.82 & $-0.08(0.6)$ & 0.09 & -0.25 & $0.31(0.65)$ & 0.49 & 0.13 & $0.04(0.98)$ & 0.31 & -0.23 \\
\hline & & & & & & & & & & & & & & & & & & \\
\hline Author, year & & Yaw ["] & & & Roll ["] & & & Pitch [ $\left.{ }^{[}\right]$ & & & iolateral & & & oposterio & & & roinferior & \\
\hline & $\operatorname{Mean}(\mathrm{SD})$ & $\operatorname{Max}$ & Min & Mean (SD) & $\operatorname{Max}$ & Min & Mean (SD) & $\operatorname{Max}$ & Min & Mean (SD) & $\operatorname{Max}$ & Min & Mean (SD) & Max & Min & Mean (SD) & Max & Min \\
\hline Ma et al. (43) & $-3.67(3.22)$ & -2.66 & -4.67 & $-1.77(2.22)$ & -1.08 & -2.46 & $0.41(2.92)$ & 1.32 & -0.50 & $-0.02(0.65)$ & 0.18 & -0.22 & $0.08(0.47)$ & 0.22 & -0.07 & $-0.09(0.40)$ & 0.04 & -0.21 \\
\hline & Mean (SD) & $\operatorname{Max}^{\dagger}$ & $\operatorname{Min}^{ \pm}$ & Mean (SD) & $\operatorname{Max}^{+}$ & $\operatorname{Min}^{+}$ & Mean (SD) & $\operatorname{Max}^{\dagger}$ & $\operatorname{Min}^{\ddagger}$ & Mean (SD) & $\operatorname{Max}^{\dagger}$ & $\operatorname{Min}^{\ddagger}$ & Mean (SD) & $\operatorname{Max}^{\dagger}$ & $\operatorname{Min}^{ \pm}$ & Mean (SD) & $\operatorname{Max}^{\dagger}$ & $\operatorname{Min}^{+}$ \\
\hline He et al. (37) & $-0.95(4.57)$ & 0.51 & -2.41 & $0.43(4.88)$ & 1.99 & -1.13 & $0.54(11.60)$ & 4.25 & -3.17 & $0.12(0.81)$ & 0.38 & -0.14 & $-0.18(0.82)$ & 0.08 & -0.44 & $0.13(1.00)$ & 0.45 & -0.19 \\
\hline & $-1.33(3.64)$ & -0.27 & -2.39 & $0.32(2.94)$ & 1.17 & -0.53 & $-1.09(12.57)$ & 2.56 & -4.74 & $-0.06(0.73)$ & 0.15 & -0.27 & $-0.26(0.76)$ & -0.04 & -0.48 & $0.01(0.71)$ & 0.22 & -0.20 \\
\hline Park et al. (38) & $-0.64(4.77)$ & 1.14 & -2.42 & $-2.99(6.3)$ & -0.64 & -5.34 & $3.06(5.86)$ & 5.25 & 0.87 & $-0.9(1.8)$ & -0.23 & -1.57 & $0.33(1.68)$ & 0.96 & -0.30 & $-1.05(1.38)$ & -0.53 & -1.57 \\
\hline & $0.88(4.49)$ & 2.87 & -1.11 & $-2.79(5.26)$ & -0.46 & -5.12 & $0.91(5.46)$ & 3.33 & -1.51 & $-0.65(0.96)$ & -0.22 & -1.08 & $0.43(1.30)$ & 1.01 & -0.15 & $-0.87(1.33)$ & -0.28 & -1.46 \\
\hline
\end{tabular}

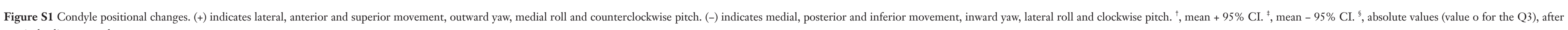
surgical splint removal. 


\begin{tabular}{|c|c|c|c|c|c|c|c|c|c|c|c|c|}
\hline & & & & & & & & & & & & \\
\hline Author year & & Yaw $\left[{ }^{\circ}\right]$ & & & Roll ["] & & & Pitch ["] & & & iolateral & \\
\hline & Mean (SD) & Max & Min & Mean (SD) & $\operatorname{Max}$ & Min & Mean (SD) & $\operatorname{Max}$ & Min & Mean (SD) & $\operatorname{Max}$ & Min \\
\hline Lim et al. (9) & $-3.4(4)$ & -1.7 & -5.1 & - & - & - & - & - & - & - & - & - \\
\hline & $-4.3(2.5)$ & -3.1 & -5.6 & - & - & - & - & - & - & - & - & - \\
\hline & $-2.3(2.8)$ & -0.9 & -3.7 & - & - & - & - & - & - & - & - & - \\
\hline Liet al. (1) & $-3.93(3.92)$ & 4.46 & -10.25 & $-0.1(2.4)$ & 3.20 & -5.05 & - & - & - & $0.50(0.90)$ & 2.56 & -1.27 \\
\hline & $-3.06(3.37)$ & 3.67 & -9.59 & $-0.4(3.1)$ & 5.17 & -5.25 & - & - & - & $1.50(1.60)$ & 5.18 & -0.27 \\
\hline Han et al. (28) & $-2.70(3.13)$ & 2.83 & -11.63 & $-1.01(3.48)$ & 5.91 & -6.19 & - & - & - & $1.30(0.97)$ & 5.09 & -0.31 \\
\hline & Mean (SD) & $\operatorname{Max}^{\dagger}$ & $\operatorname{Min}^{\ddagger}$ & Mean (SD) & $\operatorname{Max}^{\dagger}$ & $\operatorname{Min}^{\ddagger}$ & Mean (SD) & $\operatorname{Max}^{\dagger}$ & $\operatorname{Min}^{ \pm}$ & Mean (SD) & $\operatorname{Max}^{\dagger}$ & $\operatorname{Min}^{ \pm}$ \\
\hline Sander et al. (30) & $2.93(4.46)$ & 3.93 & 1.93 & - & - & - & - & - & - & - & - & - \\
\hline & $0.75(4.94)$ & 1.86 & -0.36 & - & - & - & - & - & - & - & - & - \\
\hline Xi et al. (21) & $-0.34(3.99)$ & 0.50 & -1.18 & $3.42(2.85)$ & 4.02 & 2.82 & $1.13(2.1)$ & 1.57 & 0.69 & - & - & - \\
\hline & $0.09(3.68)$ & 1.72 & -1.54 & $4.51(2.18)$ & 5.48 & 3.54 & $2.84(2.41)$ & 3.91 & 1.77 & - & - & - \\
\hline Xiet al. (3) & $1.0(4.0)$ & 1.8 & 0.2 & $3.6(3.0)$ & 4.2 & 3.0 & $1.6(4.1)$ & 2.4 & 0.8 & - & - & - \\
\hline Liet al. (1) & $-5.17(2.29)$ & -4.03 & -6.31 & $-0.62(2.82)$ & 0.78 & -2.02 & - & - & - & $0.76(0.84)$ & 1.18 & 0.34 \\
\hline & $-2.69(4.85)$ & -0.28 & -5.10 & $0.42(1.86)$ & 1.34 & -0.50 & - & - & - & $0.20(0.82)$ & 0.61 & -0.21 \\
\hline & $-3.92(3.81)$ & -2.03 & -5.81 & $-1.55(3.43)$ & 0.16 & -3.26 & - & - & - & $1.69(2.10)$ & 2.73 & 0.65 \\
\hline & $-2.21(2.96)$ & -0.74 & -3.68 & $0.74(2.58)$ & 2.02 & -0.54 & - & - & - & $1.30(1.15)$ & 1.87 & 0.73 \\
\hline Hwang et al. (24) & $2.70(3.13)$ & 7.68 & -2.28 & - & - & - & - & - & - & $1.04(0.65)$ & 1.24 & 0.84 \\
\hline & $-4.53(2.2)$ & -3.89 & -5.17 & - & - & - & - & - & - & $-0.57(0.29)$ & -0.40 & -0.74 \\
\hline Tyan et al. (32) & $-0.01(2.44)$ & 1.13 & -1.15 & $-0.29(3.26)$ & 1.24 & -1.82 & - & - & - & - & - & - \\
\hline & $-0.92(3.62)$ & 0.77 & -2.61 & $1.14(2.85)$ & 2.47 & -0.19 & - & - & - & - & - & - \\
\hline Choi et al. (35) & $-2.30(6.54)$ & 0.14 & -4.74 & $-0.94(2.75)$ & 0.09 & -1.97 & - & - & - & - & - & - \\
\hline & $-2.20(3.36)$ & -0.95 & -3.45 & $-1.02(3.11)$ & 0.14 & -2.18 & - & - & - & & & \\
\hline Park et al. (33) & $-0.52(4.1)$ & 0.87 & -1.91 & $-1.42(2.92)$ & -0.43 & -2.41 & - & - & - & $0.03(3.79)$ & 1.31 & -1.25 \\
\hline & $-1.36(3.82)$ & 1.83 & -4.55 & $-0.30(3.58)$ & 2.69 & -3.29 & & & & $-0.03(4.64)$ & 3.85 & -3.91 \\
\hline & $-0.28(4.21)$ & 1.35 & -1.91 & $-1.74(2.29)$ & -0.85 & -2.63 & & & & $0.04(3.61)$ & 1.44 & -1.36 \\
\hline Choi et al. (26) & $-2.48(4.19)$ & -0.92 & -4.04 & $-1.8(3.88)$ & -0.35 & -3.25 & - & - & - & - & - & - \\
\hline & $-2.72(4.27)$ & -1.13 & -4.31 & $-0.98(4.45)$ & 0.68 & -2.64 & - & - & - & - & - & - \\
\hline Rokutanda et al. (42) & $10.8(9.4)$ & - & - & - & - & - & - & - & - & - & - & - \\
\hline & $8.1(5.9)$ & - & - & - & - & - & - & - & - & - & - & - \\
\hline & $3(6.5)$ & - & - & - & - & - & - & - & - & - & - & - \\
\hline & & & & & & & & & & & & \\
\hline Author year & & Yaw [0] & & & Roll ["] & & & Pitch ["] & & & iolateral & \\
\hline & Mean (SD) & $\operatorname{Max}^{\dagger}$ & $\operatorname{Min}^{\ddagger}$ & Mean (SD) & $\operatorname{Max}^{\dagger}$ & $\operatorname{Min}^{\ddagger}$ & Mean (SD) & $\operatorname{Max}^{\dagger}$ & $\operatorname{Min}^{\ddagger}$ & Mean (SD) & $\operatorname{Max}^{\dagger}$ & $\operatorname{Min}^{ \pm}$ \\
\hline Yang et al. (25) & $-1.50(3.76)$ & 0.02 & -3.02 & $1.46(4.69)$ & 3.35 & -0.43 & - & - & - & - & - & - \\
\hline & $-3.95(2.96)$ & -2.48 & -5.42 & $1.53(2.73)$ & 2.89 & 0.17 & - & - & - & - & - & - \\
\hline & $-1.53(4.22)$ & 0.17 & -3.23 & $-0.5(5.62)$ & 1.77 & -2.77 & - & - & - & - & - & - \\
\hline & $-2.19(1.89)$ & -1.25 & -3.13 & $0.57(3.95)$ & 2.53 & -1.39 & - & - & - & - & - & - \\
\hline Tyan et al. (32) & $1.00(1.81)$ & 1.85 & 0.15 & $-0.67(2.60)$ & 0.55 & -1.89 & - & - & - & - & - & - \\
\hline & $0.36(3.67)$ & 2.08 & -1.36 & $0.02(3.90)$ & 1.85 & -1.81 & - & - & - & - & - & - \\
\hline Rokutanda et al. (42) & $5.5(7.1)$ & - & - & - & - & - & - & - & - & - & - & - \\
\hline & $4.1(6.2)$ & - & - & - & - & - & - & - & - & - & - & - \\
\hline & $-0.3(6.6)$ & - & - & - & - & - & - & - & - & - & - & - \\
\hline Kim et al. (2) & - & - & - & 1.48 (?) & - & - & $1.93(?)$ & - & - & $0.21(0.569)$ & 0.550 & -0.130 \\
\hline & - & - & - & - & - & - & - & - & - & $0.02(0.525)$ & 0.220 & -0.180 \\
\hline & & & & & & & & & & & & \\
\hline Author year & 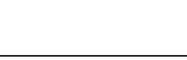 & Yaw $\left[^{\circ}\right]$ & & & Roll ["] & & & Pitch ["] & & & iolateral & \\
\hline & Mean (SD) & $\operatorname{Max}$ & Min & Mean & $\operatorname{Max}$ & Min & Mean (SD) & $\operatorname{Max}$ & Min & Mean (SD) & $\operatorname{Max}$ & Min \\
\hline Han et al. (28) & $-0.95(3.00)$ & 2.18 & -6.12 & $-1.34(3.06)$ & 5.68 & -10.46 & - & - & - & $0.33(0.88)$ & 4.18 & -1.63 \\
\hline & Mean (SD) & $\operatorname{Max}^{\dagger}$ & $\operatorname{Min}^{\ddagger}$ & Mean (SD) & $\operatorname{Max}^{\dagger}$ & $\operatorname{Min}^{\ddagger}$ & Mean (SD) & $\operatorname{Max}^{\dagger}$ & $\operatorname{Min}^{ \pm}$ & Mean (SD) & $\operatorname{Max}^{\dagger}$ & $\operatorname{Min}^{ \pm}$ \\
\hline Liet al. (1) & $-3.68(3.52)$ & -2.19 & -5.17 & $-1.22(3.37)$ & 0.92 & -3.36 & - & - & - & $0.08(0.58)$ & 0.45 & -0.29 \\
\hline & $-1.68(1.36)$ & -0.82 & -2.54 & $0.44(2.8)$ & 3.38 & -2.50 & - & - & - & $0.29(1.14)$ & 1.49 & -0.91 \\
\hline & $-4.71(1.59)$ & -3.92 & -5.50 & $-1.76(3.96)$ & 0.21 & -3.73 & - & - & - & $0.02(0.64)$ & 0.34 & -0.30 \\
\hline & $-2.66(4.60)$ & -0.37 & -4.95 & $-0.68(2.73)$ & 0.68 & -2.04 & - & - & - & $-0.18(0.53)$ & 0.08 & -0.44 \\
\hline & $-1.73(1.62)$ & -0.92 & -2.54 & $-0.58(3.33)$ & 1.08 & -2.24 & - & - & - & $0.47(1.20)$ & 1.07 & -0.13 \\
\hline & $-1.63(1.20)$ & -1.03 & -2.23 & $1.45(1.91)$ & 2.40 & 0.50 & - & - & - & $0.10(1.16)$ & 0.68 & -0.48 \\
\hline Kim et al. (29) & $-3.58(4.19)$ & -1.50 & -5.66 & $-2.41(5.20)$ & 0.18 & -5.00 & - & - & - & $0.72(1.21)$ & 1.32 & 0.12 \\
\hline & $-1.97(2.64)$ & -0.66 & -3.28 & $2.19(3.69)$ & 4.02 & 0.36 & - & - & - & $0.03(1.06)$ & 0.56 & -0.50 \\
\hline & $-3.14(4.15)$ & -0.84 & -5.44 & $1.31(3.17)$ & 3.07 & -0.45 & - & - & - & $0.36(2.06)$ & 1.50 & -0.78 \\
\hline & $-2.00(3.73)$ & 0.07 & -4.07 & $3.40(3.10)$ & 5.12 & 1.68 & - & - & - & $-0.11(1.28)$ & 0.60 & -0.82 \\
\hline & $-3.47(4.98)$ & -0.99 & -5.95 & $-1.50(4.21)$ & 0.59 & -3.59 & - & - & - & $0.41(1.40)$ & 1.11 & -0.29 \\
\hline & $-3.75(3.44)$ & -2.04 & -5.46 & $-0.22(3.83)$ & 1.68 & -2.12 & - & - & - & $0.03(0.76)$ & 0.41 & -0.35 \\
\hline Berge et al. (34) & - & - & - & - & - & - & - & - & - & $0.01(2.95)$ & 2.48 & -2.46 \\
\hline & - & - & - & - & - & - & - & - & - & $0.08(1.70)$ & 1.30 & -1.14 \\
\hline Park et al. (33) & $-0.57(3.66)$ & 0.67 & -1.81 & $-1.36(3.3)$ & -0.24 & -2.48 & - & - & - & $-0.90(3.96)$ & 0.44 & -2.24 \\
\hline & $-0.87(4.44)$ & 2.84 & -4.58 & $0.29(3.75)$ & 3.43 & -2.85 & & & & $-1.43(2.24)$ & 0.44 & -3.30 \\
\hline & $-0.50(3.42)$ & 0.83 & -1.83 & $-1.82(3.23)$ & -0.57 & -3.07 & & & & $-0.75(3.82)$ & 0.73 & -2.23 \\
\hline Tyan et al. (32) & $0.36(0.52)$ & 0.60 & 0.12 & $-0.95(0.54)$ & -0.70 & -1.20 & - & - & - & - & - & - \\
\hline & $0.63(0.98)$ & 1.09 & 0.17 & $-0.33(0.99)$ & 0.13 & -0.79 & - & - & - & - & - & - \\
\hline Choi et al. (26) & $-0.33(2.22)$ & 0.50 & -1.16 & $-0.47(1.42)$ & 0.06 & -1.00 & - & - & - & - & - & - \\
\hline & $0.02(2.03)$ & 0.78 & -0.74 & $-0.14(0.57)$ & 0.07 & -0.35 & - & - & - & - & - & - \\
\hline Choi et al. (35) & $0.17(4.76)$ & 1.95 & -1.61 & $-0.53(4.85)$ & 1.28 & -2.34 & - & - & - & - & - & - \\
\hline & $0.10(2.63)$ & 1.08 & -0.88 & $-0.22(2.87)$ & 0.85 & -1.29 & - & - & - & - & - & - \\
\hline Rokutanda et al. (42) & $4.1(6.0)$ & - & - & - & - & - & - & - & - & - & - & - \\
\hline & $4.5(7.1)$ & - & - & - & - & - & - & - & - & - & - & - \\
\hline & $-0.3(6.6)$ & - & - & - & - & - & - & - & - & - & - & - \\
\hline & & & & & & & & & & & & \\
\hline Author & & Yaw [0] & & & Roll ["] & & & Pitch ["] & & & iolateral & \\
\hline & Mean (SD) & $\operatorname{Max}^{\dagger}$ & $\operatorname{Min}^{\ddagger}$ & Mean (SD) & $\operatorname{Max}^{\dagger}$ & $\operatorname{Min}^{\ddagger}$ & Mean (SD) & $\operatorname{Max}^{\dagger}$ & $\operatorname{Min}^{ \pm}$ & Mean (SD) & $\operatorname{Max}^{\dagger}$ & $\operatorname{Min}^{ \pm}$ \\
\hline Tyan et al. (32) & $0.86(2.78)$ & 2.16 & -0.44 & $-2.26(2.74)$ & -0.98 & -3.54 & - & - & - & - & - & - \\
\hline & $0.53(3.82)$ & 2.32 & -1.26 & $0.33(2.74)$ & 1.61 & -0.95 & - & - & - & - & - & - \\
\hline Rokutanda et al. (42) & $5.8(4.9)$ & - & - & - & - & - & $\begin{array}{ll}- & \text { - }\end{array}$ & - & - & - & $\begin{array}{lll}- & \\
\end{array}$ & - \\
\hline & $5.6(6.5)$ & - & - & - & - & - & - & - & - & - & - & - \\
\hline & $-12(5.1)$ & - & - & - & - & - & - & - & - & - & - & - \\
\hline
\end{tabular}

